\title{
FRUIT DEVELOPMENT, THE SEXUAL PROCESS, AND ABSCISSION IN CITRUS FOLLOWING POLLINATION
}

By

JUAN TABILANGON CARLOS, JR.

\begin{abstract}
A DISSERTATION PRESENTED TO THE GRADUATE COUNCK OF THE UNIVERSITY OF FLORIDA

IN PARTLAL FULFILLMENT OF THE REQUIREMENTS FOR THE DEGREE OF DOCTOR OF PHLOSOPHY
\end{abstract}

UNIVERSITY OF FLORIDA

1968 
MY PEOPLE 


\section{ACKNOWLEDGEMENTS}

This research was conducted with the supervision and guidance of Dr. A. H. Krezdorn, Professor and Chairman, Department of Fruit Crops, University of Florida, to whom the writer expresses deep gratitude for his unfailing help and encouragement.

Sincere appreciation is extended to Dr. R. H. Biggs, Professor and Biochemist, Department of Fruit Crops;

Dr. W. C. Wilson, Plant Physiologist, Citrus Experiment Station; and Dr. J. H. Davis, Jr., Professor, Department of Botany for their constructive criticisms in the preparation of this work and their participation in the writer's supervisory committee.

The writer is grateful to the University of the Philippines and the Rockefeller Foundation for giving him the opportunity to pursue graduate work.

The field work in this experiment was made possible with the assistance of most of the graduate students in the Department of Fruit Crops in 1967 and 1968; their help is warmly acknowledged. The assistance of Eng. James Russell Coldren in photography is sincerely appreciated.

Last, but not least, the writer wishes to thank his wife, children, and family who were always a source of encouragement and inspiration. 
TABLE OF CONTENTS

Page

ACKNOWLEDGEMENTS . . . . . . . . . . . . . . . . iii

LIST OF TABLES . . . . . . . . . . . . . . . . . . v

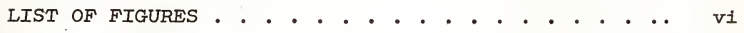

INTRODUCTION . . . . . . . . . . . . . . . . . . . . . . . . 1

REVIEW OF LITERATURE . . . . . . . . . . . . . . 3

MATERIALS AND METHODS . . . . . . . . . . . . 33

RESULTS . . . . . . . . . . . . . . . . . . . . 37

DISCUSSION . . . . . . . . . . . . . . . . . . 79

SUMMARY AND CONCLUSION . . . . . . . . . . . . . 94

LITERATURE CITED . . . . . . . . . . . . . . 98

BIOGRAPHICAL SKETCH . . . . . . . . . . . . . 112 


\section{LIST OF TABLES}

Table

1. Growth of Pollen Tubes Inside the Pistil of 'Orlando' Tangelo at Various Dates Following GA-Treatment and Pollination. . . . 40

2. Abscission of 'Orlando' Tangelo Ovaries During the 2 Main Abscission Periods as Influenced by GA and Pollination. . . . . . 50

3. Time from Pollination to Specific Stages of Development of the Pistil, Fruit, and Seed in Cross-Pollinated Flowers of 'Orlando' Tangelo............. . . 61

4. Fruit Set, Fruit Size, and Number of Seeds

Per Fruit as Influenced by GA-Treatment and Pollination. . . . . . . . . . . . 77 


\section{LIST OF FIGURES}

Figure

Page

1. Pollen Grain of Citrus Germinating on the Stigmatic Surface of 'Orlando' Tangelo.

2. Longitudinal Section of 'Orlando' Tangelo Style 2 to 6 Days After Pollination. . . . 39

3. Pollen Tube Inside 'Orlando' Tangelo Ovule, 6 and 10 Days After Pollination in 1968 and 1967, Respectively. . . . . . . . 41

4. Abscission Layer at the Base of the style of 'Orlando' Tangelo Pistil, 6 days After Full Bloom in 1968.

5. Separation Layer at the Base of 'Orlando' Tangelo Pistil, 8 Days After Full Bloom in 1968.

6. Discoloration and Abscission of 'Orlando' Tangelo Styles and Pistils. . . . . . . 46

7. Notch at the Base of the Pedicel at Which Young Flowers Before and Soon After Anthesis Abscised.

8. Pedicel of 'Orlando' Tangelo Flower Showing Abscission Zone Between 2 Vegetative Buds.

9. Rate of Ovary Abscission in 'Orlando' Tangelo

10. Early Stage of Nucellar Contraction Indicating Lack of Fertilization, 10 Days After

Pollination.

11. Advanced Stage of Nucellar Contraction in

'Orlando' Tangelo Indicating Lack of

Sexual Fertilization, 14 Days After

Pollination.

12. Cross-Section of 'Orlando' Tangelo Ovules in Advanced Stage of Nucellar Contraction, 14

Days After Pollination. 
13. Undivided Zygote and Multinucleate Endosperm of 'Orlando' Tangelo 14 Days After Pollination.

14. Undivided Zygote and Multinucleate Endosperm of 'Orlando' Tangelo 14 Days After Pollination.

15. Longitudinal Section of 'Orlando' Tangelo Seed 65 Days After Pollination. . . . . . 62

16. Sexual Embryo and Cellular Endosperm of 'Orlando' Tangelo, 80 Days After Pollination or 10 Weeks After Stylar Abscission. . . .

17. Undivided Zygote and Nucellar Embryo of 'Orlando' Tangelo, 40 Days After Pollination or 5 Weeks After Stylar Abscission. . . . . . . . 64

18. Binucleated Zygote of 'Orlando' Tangelo, 40 Days After Pollination or 5 Weeks After Stylar Abscission.

19. Young Embryos of 'Orlando' Tangelo, 50 Days After Pollination or 42 Days After Stylar Abscission.

20. Young Embryo of 'Orlando' Tangelo, 50 Days After Pollination or 42 Days After stylar Abscission. . . . . . . . . . 68

21. Sexual and Nucellar Embryos in 'Orlando' Tangelo Seed 85 Days After Pollination. . . . . . 69

22. Zygotic and Nucellar Embryos in 'Orlando' Tange10, 90 Days After Full Bloom (12 Weeks After Abscission of the Style). . . . 70

23. Growth Curve of 'Orlando' Tangelo Fruit With Corresponding Stages of Floral Abscission and Seed Development. . . . . . . . . 73

24. Growth Rate of 'Orlando' Tangelo Fruit. . . . 76 
Abstract of Dissertation Presented to the Graduate Council in Partial Fullfillment of the Requirements for the Degree of Doctor of Philosophy

\section{FRUIT DEVELOPMENT, THE SEXUAL PROCESS, AND ABSCISSION IN CITRUS FOLLOWING POLLINATION}

BY

Juan Tabilangon Carlos, Jr. December, 1968

Chairman: Dr. A. H. Krezdorn

Major Department: Fruit Crops

Experiments using flowers and fruits of 'Orlando' tangelo, Citrus paradisi Macf. x $\underline{\text { C. reticulata }}$ Blanco, were conducted to determine possible relationships between growth of the pollen tubes, abscission of flowers and their styles, development of the seed, and development of the fruit. Pistils and young fruits were collected at various intervals, killed and fixed in FAA, sectioned or squashed, and stained following standard techniques.

Pollen grains germinated and their tubes grew down the style irrespective of treatment. Tubes of compatible, but not incompatible polien entered the ovary before the style abscised. There was evidence that physical blockage of the stylar canals did not prevent incompatible pollen tubes from entering the ovary but that physiological senescence of the stylar base prior to abscission may have prevented pollen tube growth past that point.

Discoloration of the style coincided with the entrance 
of the pollen tubes into the ovule. Stylar abscission occurred at the same time as the initial division of the endosperm nucleus. These events preceded by less than a week the first peak in the relative increments of both growth and abscission of young fruits. A second peak in fruit abscission occurred 43 to 50 days after pollination. At this time, initial division of the zygote and the second peak in the per cent increase of fruit growth also occurred. This was approximately the transition point between the first and second stage of the sigmoid curve in fruit growth. The endosperm turned cellular 5 days before the last fruit in the "June Drop' period abscised. This was in the second stage of the growth curve, at which time the fruit was enlarging at increasing rates. Coincident with the end of the second stage of fruit growth and the start of the slower rate of growth in stage 3 was the complete absorption of the endosperm. Ten days later, first seed germination occurred. 


\section{INTRODUCTION}

The discovery of chemical regulators of growth and development has introduced materials which when applied in very small quantities at the correct stage of development of the plant, or one of its organs, produce large morphological and physiological changes. These effects of basic cellular processes offer utility in such horticultural practices as rooting of cutting, fruit thinning, fruit setting, and fruit storage.

The use of growth regulators in agriculture has often resulted in very erratic responses. The cause of these inconsistent results has frequently been attributed to their application at incorrect stages of development of the plant organ being affected. For example, commercial thinning of peaches with a-naphthaleneacetic acid (NAA) was not successful until it was determined that the material was most effective when applied at a specific stage of fruit development which coincided with the cytokinetic stage of endosperm development $(108,114)$.

In attempts to improve fruit set and yields of citrus with gibberellic acid (GA), results have been erratic ( 41 , 42, 43,84). Moreover, the effects on the morphological features of the plant by GA are related to the stage of development of the plant or plant organ to which it is applied. 
It had been shown that when GA was applied during the full bloom stage, leaf abscission was directly related to the concentration of the material but when applied in the post bloom stage, no abscission was observed with similar concentrations (102).

Undoubtedly, the morphological indicators of a given developmental stage only reflect the physiological status of the plant but are useful because they are more easily determined than is its physiological status. This has been recognized in peaches (115) and cherries (116) where detailed studies have shown that style abscission is a good physiological reference point. Fruit size has also been reported as a useful parameter (108).

Bain (16) has described the development of the citrus fruit very we11. However, information on the abscission of the floral parts (151), growth of the pollen tube $(166,167)$, and development of the embryo $(15,17)$ is limited and no determination has been made as to whether these developmental stages might be related.

The objectives of this work were to (1) determine relations existing between abscission of styles, ovaries, and young fruits; growth of the pollen tubes; development of the fruit, and development of the seeds in the self-incompatible 'Orlando' tangelo (Citrus paradisi Macf. x C. reticulata Blanco); and (2) compare pollen tube growth and abscission of styles, ovaries, and young fruits with the initial stages of seed development as affected by GA, cross-pollination, and self-pollination. 
REVIEW OF LITERATURE

\section{The Citrus Flower and Fruit}

\section{The Flower}

\section{Flowering characteristics}

Flower bud induction in sweet orange takes place 3-4 weeks before morphological indications of differentiation (127,140) which are evident with the advent of the growing period in spring $(2,19,66,21)$.

The principal blooming period for citrus in the northern hemisphere is usually in the spring, mainly in March and April $(21,177)$. This period varies somewhat, depending on enviromental conditions, species, varieties, and cultural practices ( 21 ). An extended cold winter delays flowering, while an early, warm spring accelerates it (14). Off-season blooms may be observed during other seasons but these flowers constitute a minor part of the total bloom (21).

Two types of inflorescences in citmus have been described (141). The bouquet or leafless bloom consists of flowers borne in the axils of leaves of previous growth flushes. Leafy bloom consists of flowers borne on new, leafy shoots. Either type of bloom may consist of one or more individual flowers.

The potential of each type of flower to develop to mature 
fruit varies. Leafy inflorescences reportedly produced a higher fruit set than leafless ones (141). Moreover, flowers at the tips of flowering shoots had higher percentage of fruit set than those below.

Morphology of the citrus flower

Typical of angiosperms, the citrus flower consists of more or less united sepals or calyx, a whorl of petals or corolla, stamens, a pistil, and a disk or nectary (21).

The calyx of a mature citrus flower is a cup-like structure at the base of the petals, usually having 5 projections along the rim. The corolla has 4 to 5 , heavily cutinized, glossy petals which are generally white in color.

The number of stamens range from 20 to 40 per flower, each having a filament with a yellow, 4-lobed anther containing the pollen. The pistil consists of an expanded stigma. with unicellar hairs that secrete a viscous fluid for the retention and germination of the pollen grains, a cylindrical style with canals extending from the stigmatic surface to the locules in the ovary; and the ovary with several ovules in each locule.

The citrus pistil is basically composed of approximately 10 joined units, the carpels, each of which extend from the ovary to the stigmatic surface. The inner margins of each carpel are joined with another around the central axis (core) of the ovary. The placenta, which bears the ovules, develops from the inner angles of the locule. Ford (72) indicated the ovules arise from the carpellary margins but Osawa (136) considered the axis of the ovary as the origin 
of the plaoenta.

A citrus ovule assumes an anatropous form with the micropyle facing the axis of the ovary. It consists of a funiculus, a central mass of nucellar tissue, the embryo sac, inner and outer integuments, and the micropyle (136).

The ovary rests on a cup-like structure, the disk, just above the receptacle to which the stamens and petals are attached. The outer portions of the disk (nectary) secrete a watery fluid.

The Citrus Fruit

\section{Fruit morphology}

The citrus fruit is a mature ovary (21). Morphologically, it is a modified berry termed a hesperidium. The seeds are embedded in the flesh which consists of fleshy endocarp hairs.

The leathery peel of a citrus fruit consists of 2 distinct parts. The outer, colored portion is composed of the epicarp, the hypoderm, and the outer mesocarp collectively called the flavedo (21). The inner mesocarp or albedo is spongy and generally white.

Several segments in the mature fruit, each corresponding to a carpel in the ovary, contain the juice vesicles or fleshy endocarp hairs. The seeds inside are attached to the carpellary margins toward the central core.

\section{Fruit growth and development}

Most citrus fruits are set in late spring but reach full maturity after varying lengths of time, depending on the variety or species, age of the tree, and environmental 
conditions during the growth period.

Bain (16) determined 3 stages of development for 'Valencia' fruit, each stage corresponding to changes in growth rate during the year. The initial slow-growth period which lasted 4 to 9 weeks from full bloom was the cell division stage. The period of maximum growth which lasted 29 weeks was a period of cell enlargement. Morphological, anatomical, and physiological changes during this period were also rapid. Stage III or the maturation period was characterized by the color break of the rind and decreased rates of morphological, anatomical, and physiological changes.

The same general growth pattern as in 'Valencia' was shown for 'Washington' navel fruits (180).

\section{The Sexual Process}

\section{Pollination, Pollen Tube Growth, and Fertilization}

Pollination refers to the transfer of pollen from the anther to the stigma. Fertilization is the fusion of a sperm nucleus with an egg nucleus.

Cultivated varieties of citmus are generally self-and cross-compatible (74). A few are self-incompatible, therefore seedless, and often unfruitful when selfed $(1,27,32$, $74,135,142,154,155,166,167)$.

Cross-pollination in citrus is mainly entomophylous (169, 176). In trees having compatible pollen, it was shown that seedy fruits set on branches that were bagged to exclude insects (169). It was further noted that for protandrous species, self-pollination was accomplished without the help 
of insects because the anthers shed their pollen even while still pressed against the stigma in the unopened or opening flower.

The pollen germinates on the thick, sticky liquid secreted by the stigma. The pollen tubes enter the stylar canals at the surface of the stigma and grow through these canals to the corresponding locules of the ovary (21). Each pollen tube grows through the micropyle and nucellus, entering the embryo sac at its apex. A sperm nucleus then passes into the embryo sac, disorganizing one of the synergids (15. 17), and fuses with the egg nucleus. Syngamy and double fertilization are accomplished simultaneously (17) and the antipodals degenerate (15).

Coit (39) states that the time required for complete fertilization in citrus varies with varieties, ranging from 30 hours in the Satsuma (Citrus unshiu) to 4 weeks after pollination in the related trifoliate orange (Poncirus trifoliata). In several species of citrus Strasburger, as cited by Frost (73), reported that fertilization took place 4 weeks after pollination. Osawa (136) thought that in Poncirus trifoliata, fertilization occurred more than 2 weeks, but probably not more than 4 weeks, after flowering. On the other hand, only 4 days elapsed between pollination and fertilization in the 'Foster' grapefruit (15). Hensz (83) reported that 'Duncan' pollen tubes penetrated the embryo sac of 'Orlando' tangelo 4 and 12 days after pollination in 1963 and 1962, respectively. Ton and Krezdorn (167) 
showed that in 3 cultivars of citrus, the number of days required for pollen tubes to reach the ovule ranged from 5 to 8 days after pollination.

Sexual Incompatibility in Plants

Early concepts of sexual incompatibility in plants are not clearly distinguished, if at all, from the phenomenon of sterility. Hayes and Garber (82) defined sterility as "the inability to produce viable seeds; when male and female gametes, through incompatibility or some other causes, are incapable of mating or fertilization." Thus, these terms wene used interchangeably by plant breeders and plant geneticists $(56,57,58,62,139)$. Later, Stout (162) defined self-and cross-incompatibility as "selective physiological reactions in fertilization which limit or prevent self-fertilization in certain hermaphrodites and cross-fertilization between certain of these self-incompatible individuals, and in case there are self-compatible plants which carry factors for incompatibility, such plants may also be involved in cross-incompatibility." Sterility on the other hand has been described as resulting from the failure of any of the reproductive organs to be differentiated or to develop fully or from failure to function normally (62). Thus, the inability to produce viable seeds among incompatible plants is not due to the sterility of either the male or female organs but to their being brought together in the wrong combination (111).

The presence of incompatibility mechanisms in plants has been observed in many plant groups. East (56) estimated 
that incompatibility could be found in no less than 3,000 species distributed within 20 families of flowering plants. Lewis (111) believed that this figure was probably a small fraction of the actual number of incompatible species. Systems of sexual incompatibility

Two types of incompatibility systems are generally recognized by plant breeders and geneticists (111). These are heteromorphy and homomorphy. The former is associated with differences in floral structure such as length of the styles and height of the anthers. Self-incompatible plants of the latter type have no structural differences in their flowers.

Heteromorphic self-incompatibility is further subdivided into distyly and tristyly. In distyly, 2 types of flowers are present: the thrum, which has a short style and high anther; and the pin, which has a long style and low anther. In tristyly, 3 types of flowers (long-, mid-, and short-styled) are present.

Differences in floral structures are accompanied by incompatibility such that only pollinations between pin and thrum plants, that is between anthers and styles at the same levels, are fertile. Pollinations between flowers of the same plants, where the anther and style are at different levels, are either completely or partially sterile (111). It was also shown that thrum pollen is larger than pin pollen and the cells of the thrum stigmas are smaller than those of the pin type. 
Each of the 3 types of flowers in tristyly have anthers at 2 different levels, the stigma being at a level different from both sets of anthers. Compatible pollinations are between stigmas and anthers of the same levels. Pollinations between stigmas and anthers of different levels are incompatible (111).

Explanations for the genetic control of both the distyly and tristyly types of heteromorphic self-incompatibility have been proposed $(56,57)$.

Lewis (111) reported that the homomorphic type of selfincompatibility in plants dates back to the time of Darwin although no explanations were given for its occurrence until 1913. He cited Correns who took the position that certain "Iine stuff" inhibited cross-pollination between 1ines. When this factor is present in both the pollen and the style, pollination would be incompatible and that this would very likely be a self-incompatible species. This type of selfincompatibility is also known as the Nicotiana type, personate incompatibility, or inoompatibility due to oppositional factors (111). This type of incompatibility system is found in Nicotiana sanderae (57); Denothera $(63,111)$; apples and pears (44, 126); cherry and plum (110); and lily (64).

Other types of incompatibility different from those mentioned above exist. In cacao, Mather (123) reported the pollen tube was normal and the eggs were fertilized but the development of the embryo was arrested. The same type of incompatibility was observed in Gasteria species (150). 


\section{Physiology of sexual incompatibility}

Two positions are commonly taken to explain the physiological basis of self-incompatibility in plants. These are positive inhibition $(13,56,109,126,150)$ and the absence of stimulation $(28,29,58,172)$ by the style or stigma on the pollen. In studying the behavior of pollen tubes in selfand cross-pollinations, Cooper (44) concluded that the growth of pollen tubes in case of self-pollinations seemed to be retarded by some factor or that the growth of the pollen tubes in the crosses were accelerated.

The inhibition theory assumes that incompatibility is due to a reaction between the pollen and the style (56). The pollen tube passes down the stylar tissue intercellularIy and that pollen tube secretions act as antigens against the stylar tissues of incompatible plants. This stylar tissue in turn forms antibodies which inhibit the growth of the pollen tube.

This theory was supported by Sears (150) who pointed out that in species in which incompatible pollen fails to germinate, it would be difficult to explain incompatibility on the lack of stimulation because pollen will germinate even in moist air. Attia (13) also showed that an inhibiting substance was present in high concentration on the style of self-incompatible cabbage plants. Thus, Lewis (109) concluded that incompatibility is not due to a negative effect or lack of some growth substances, but to an active production of specific substances in the pollen and style 
which interact to stop the growth of the tube. This inhibiting substance may account for the swelling of the pollen tube end which Modlibowska (126) found among incompatible apples and pears.

East and Park (58) on the other hand reported that pollen tubes in a selfed pistil are not inhibited in their growth by any substance secreted in that pistil. Instead, a substance or substances are secreted in the pistil following a compatible cross which accelerated growth. It is further thought that the direct cause of this secretion is a catalyzer that the pollen tube nucleus is able to produce. Brewbaker and Majumder (28) suggested that incompatibility in plants may be due to the limited production of a factor necessary for pollen tube growth. They showed that styles exposed to compatible crosses contain promotive materials to pollen tube growth. Pollen tube growth-promoting substances may also be present in the pollen itself (29), stigma, or style $(28,172)$.

Viewed from a different standpoint, incompatibility in plants appears to be due either to the failure of the pollen to penetrate the stigma or to the early cessation of its growth. Lewis (111) reported that incompatibilities in Brassica oleracea, Raphanus sativa, and Secale cereale are due to the inability of the pollen tube to penetrate the stigmatic surface. This type of incompatibility does not seem widespread.

Most incompatibility systems found in plants are those 
in which pollen tube growth is inhibited in the style. In petunia, Eyster (69) and Yasuda (185, 186) found that pollens of self-pollinated self-incompatible strains germinated well but the pollen tube rarely grew as far as $1 / 2$ the length of the style. Before some of the tubes reached the ovary, the style was cut off from the top of the ovary by the formation of an abscission layer. In 2 species of Nicotiana, East and Park (58) also observed that pollen tubes of incompatible matings grew steadily and apparently normally but did not reach the ovary before the flowers decayed because growth of the pollen tube was too slow. These findings were later confirmed by East and Mangelsdorf (57). In cabbage, however, Pearson (139) found that incompatibility was due to the death of the ovule before it was reached by the sperm nuclei. Pollen tubes of incompatible matings in apples and pears were completely arrested in the style, the time and place of arrest depending on the temperature prevailing at the moment (126). An incompatibility reaction which led to the swelling of the pollen tube ends was also found.

The arrest of the pollen tube half-way down the style of pears was reported by recent works of olez and Zielinski (134). In addition, it was found that the incompatibility reaction between the pollen tube and style increased in intensity through the basal portion of the style. In apples, the rate of pollen tube growth between selfed and crossed materials became different after traversing $1 / 4$ to $1 / 3$ the 
length of the style (44). It was also noted that more of the selfed than crossed flowers abscised both before and after fertilization had taken place. Lack of fertilization in cherry (Prunus avium) and plum (ㅁ. domestica) was attributed to the failure of the pollen tube to reach the ovary before the flower withered or abscised $(110,112)$.

The mechanisms of incompatibility in citrus are apparent1y quite similar to some systems found in other plants. Soost (154) reported that the reproductive parts of the selfunfruitful 'Clementine' mandarin were functional but the pollen did not seem to function well on its own stigma. He postulated that the pollen tube must have grown very slowly. Ton (166) and Ton and Krezdorn (167) showed that pollen tubes of cross-compatible 'Parson Brown' orange and 'Duncan' grapefruit definitely traversed the style of 'Orlando' tangelo much faster than did those of cross-incompatible 'Clementine' mandarin and 'Minneola' tangelo and selfincompatible 'Orlando' tangelo.

The stigma and anthers of 'Minneola' tangelo mature at the same time (129). The sperm and egg cells are also functional, since pollen germinates in artificial media and the ovules develop into normal seeds when cross-pollinated with compatible varieties. However, it is also self-unfruitful because of the inability of the pollen tube to penetrate completely to the ovule. Ton and Krezdorn (167) showed that 'Minneola' and 'Orlando' tangelo pollen tubes penetrated only $2 / 3$ and $1 / 3$ of the 'Minneola' styles, during the time 
required for 'Duncan' pollen tubes to reach the ovule. Thus, 'Minneola' fruits are seedless when selfed or cross-pollinated with 'Orlando' but seedy when compatible pollen is used (129).

Unfruitfulness in solid blocks of 'Orlando' tangelo has also been attributed to sexual self-incompatibility coupled with lack of a strong and consistent parthenocarpy (101, 103). The reproductive organs of 'Orlando' tangelo flowers are normal and functional $(83,167)$. It was reported that both 'Orlando' and 'Duncan' pollen germinated equally well on 'Orlando' stigmas and their pollen tubes grew equally well in the style (83). Later, it was shown that growths of 'Orlando' pollen tubes in 'Orlando' styles were slower than those of 'Duncan' (167). In either case, the growth of the 'Orlando' pollen tube was inhibited at the base of the style and no tubes were found penetrating the ovule. On the other hand, 'Duncan' tubes reached the ovule in 4-6 days.

Hensz (83) observed that ovaries of the 'Orlando' tangelo also abscised within 4-12 days after pollination in 1963 although he did not notice any ovary abscission the previous year. Abscission of the style was reported to have begun or been completed in 8 days after pollination (83, 166, 167). Whether or not the development of the abscission layer presented a physical barrier to the penetration of the pollen was not determined.

'Robinson' is also unfruitful when self-pollinated (142) 
Self-incompatibility in shaddock (Citrus grandis) is widespread $(1,27,156,168)$ and has been shown to be brought about by the inability of the pollen tube to traverse the style in time (155). Seedlessness and low yield in 'Washington' navel is due to the sterility of pollen and the degeneration of nearly all of the ovules during the formation of the megagametophyte (74).

Methods of overcomong incompatibility in plants

A number of workers had developed methods of overcoming incompatibility systems in some plants. East and Mangelsdorf (57) pointed out that in Nicotiana species, fertilization in self-incompatible flowers can be achieved by lengthening the life of the flower and by accelerating the growth of the pollen tube. Previously, fertilization was also accomplished by decapitating the style prior to pollination (58).

Self-pollinations made in the bud stage had been successful in several crops. In petunia, Eyster (69) found that opening immature flower buds that were beginning to develop anthocyanin in the petals and pollinating them with pollen from fully opened flowers of the same plant induced self-fertility. Pearson (139) overcame self-incompatibility common in cabbage by opening the buds and pollinating them 1 to 5 days before the flowers would normally open. Much better success was obtained with younger than older buds. Attia (13) attributed success of pollination among incompatible matings in the bud stage to the absence or insufficient 
concentration of an inhibitory substance in the young styles rather than the increased length of time afforded the pollen tube to traverse the shorter, immature styles.

$$
\mathrm{X} \text {-ray treatment, at a dosage of } 800 \mathrm{r} \text { units, of pollen }
$$

mother cells of self-incompatible sweet cherries at the resting stage increased the production of fruits and seeds about tenfold (112).

Attempts have been made to overcome incompatibility with growth regulators. Seeds developed in a self-sterile strain of petunia when the plants were sprayed with alphanaphthalene acetamide (NAd) immediately before or after they had been self-pollinated (69). In 'Easter' lilies, some clones do not set seeds when pollinated with their own pollen but readily produce seeds when sprayed with several synthetic auxins (64). It was also shown that these treatments delayed abscission of the style, increased sugars, and stimulated fruit growth. Self-incompatibility in cherries and plums, which is due to the failure of the pollen tubes to reach the ovary before the flower withers or abscises, was also overcome with NAA treatments $(110,112)$. It was shown that NAA did not affect the growth of the incompatible pollen tubes in the plums but retarded those of cherries. In both cases, however, NAA delayed abscission of the style by about 2 days. In California, Soost (155) showed that bud-pollination of self-incompatible shaddock resulted in setting of seedy fruits. He suggested that the premature dehiscence of the anthers may provide the mechanism for self-pollination of 
the buds and the bridging of the incompatibility barrier. Self-incompatibility in 'Orlando' tangelo was also overcome by pre-anthesis self-pollinations (32). It was shown that growth of pollen tubes in self- and cross-pollinations at pre-anthesis did not differ.

\section{Development of the seed}

\section{Endosperm Development}

There are 3 types of endosperm development: Cellular, Helobial, and Nuclear (21). In the Cellular type, the first and later divisions are accompanied by cell wall formation. In the Helobial type, first division of the endosperm nucleus is accompanied by cell wall formation but subsequent ones are not. Later divisions are followed by cell wall formation. The Nuclear type is characterized by the absence of cell walls in the early divisions of the endosperm nuclei. The nuclei remain free, becoming separated by walls only in later stages of development. Citrus belongs to this type $(15,17)$.

After double fertilization, the primary endosperm nucleus divides, resulting in the development of a multinucleated free endosperm. In'Foster' grapefruit, Bacchi (15) reported about 1,500 nuclei within one endosperm which remained nuclear within the 67-day sampling period. He did not observe the subsequent cellular divisions which were reported in Poncirus trifoliata (136) and Citrus grandis (17). 
Embryo Development

In gymnosperms, the first fow divisions of the zygotc are almost always free nuclear, in sharp contrast to those of the angiosperms in whieh nuelear divisions are, in almost all eases, aeeompanied by cell wall formation (120).

The maturc embryo of the monocots differ significanty from that of the dieots. However, in thc earlier stages of development there are no fundamental diffcrences between them $(120)$.

In gencral, the first division of the zygote is accompanicd by the formation of a transverse wall. The ccll towards the center of the cmbryo sae is called the terminal eell and the one towards the mieropyle, the basal eell.

Five prineipal types of cmbryos among the dieotylecions have been reeognized (120). They are distinguished from eaeh other as follows:

I. The terminal ccll of the two-eelled pro-embryo divides by a longitudinal wall -

(i) Tle basal cell plays only a minor part or nonc in the subscquent development of the embryo - - - Crueifer or Onagrad type

(ii) The basal and terminal cells eontribute to development of the embryo - - Astcrad type

II. The terminal cell of the two-cclled proembryo divides by a transverse wall -

1. The basal eell plays only a minor part or none in the subsequent development of the embryo -

(i) The basal cell usually forms a suspensor of 2 or more eells _ _ - Solanad type

(ii) The basal ecll undergoes no further division, and the suspensor, if present, is always derived from the terminal cell - Caryophyllad type

2. The basal and terminal eclis both eontribute to the devclopment of the embryo - - Chenopoiad type

Sexual embryos of plants in the family Rutaecae arc 
essentially of the Crucifer or Onagrad type (95). However, they differ from the typical Crucifer type in that quadrants are not regularly formed. This type of embryo is called the Ruta Variation, described by Johansen (95) as:

The terminal cell usually divides by an oblique wall and behaves as in the Asterad type. When the terminal cell divides vertically as in the typical fashion, the behavior of the daughter cell is peculiar: one daughter cell divides by a longitudinal wall and the other by a transverse wall. The formation of the octant stage is brought about by the formation of the longitudinal walls in the transversely divided derivatives and by transverse walls in the others.

After fertilization, the citrus zygote undergoes a long resting period ranging from 21 to 28 days in the related trifoliate orange (136) to 50 days in 'Foster' grapefruit (15). The zygote then divides according to the Ruta Variation type (95). With the differentiation of the cotyledonary lobes, the dermatogen, periblem, and plerome become clearly defined (17). The mature embryo of the monoembryonic shaddock consists of 2 large cotyledons which completely fill up the seed and an axis which bears the plumule and the radicle. It has a short (17), thin suspensor about 4 to 6 cells in diameter (136).

\section{Polyembryony in citrus}

Three types or forms of polyembryony are known in citrus: Nucellar polyembryony (39, 73, 168, 121, 170, 174, 175), which gives rise to identical, maternal seedlings derived from the nucellus; cleavage polyembryony (73), which originates through the fission of the generative embryo; and polyembryony caused by the occurrence of more than one normal gametophyte 
within one embryo $\operatorname{sac}(15,17)$.

In general, only one gametic embryo develops in a seed. In rare instances, however, more than one develop. Bacchi (15) and Banerji (17) attributed this to the presence of more than one megagametophyte within the embryo sac in the ovule. Frost (73) indicated that the possible splitting of a zygotic embryo may account for the presence of more than one sexual embryo in a seed.

Vegetative (nucellar) embryony or sporophytic budding is common in many citrus species $(73,168,121,174,175)$ and the trifoliate orange (136). Among the polyembryonic species, far more of the nucellar than gametic embryos develop in the seed. Within a variety, Majsuradze (121) indicated that if some time elapsed between fusion of the gametes and growth of the sexual embryo, nucellar embryos are likely to develop. Mamporija (122), on the other hand, reported that the proportion of gametic to nucellar embryos depended on the type of pollen used in the sexual process. He noted that 'Washington' navels and 'Unshiu' mandarins gave rise to nucellar seedlings when pollinated with trifoliate orange and to both nucellar and sexual seedlings when pollinated with Citrus ichangensis.

The presence of nucellar embryos in the seeds of most citrus varieties and species poses a problem in the production and identification of sexual seedlings. However, at earlier stage of development, the sexual embryo may be distinguished from the nucellar ones. Osawa (136) showed that zygotic embryos of trifoliate orange seeds have suspensors while 
nucellar ones do not.

\section{Development of the Seed Coat}

The seed coat of citrus develops mainly from the integuments of the ovule and whatever remains of the nucellus and endosperm (21). The inner integument arises first followed by the outer (72).

At later stages of embryonic development, the endosperm and nucellus disappear almost completely, leaving only vestiges which contribute to the formation of the seed coat. These, plus the inner integument constitute the tegmen or inner seed coat. The outer integument forms the testa or outer seed coat.

\section{Abscission}

Abscission is defined as the shedding of leaves, flowers, fruits, and stems from the parent plant (106). An abscission layer is a layer of cells, the disjunction or breakdown of which separates a plant part such as leaf, fruit, or flower from the plant (68). It is synonymous with separation layer. The zone at the base of the leaf or fruit or flower that contains the abscission and the protective layer is called the abscission zone (68).

Some differences of opinion exist as to whether or not the term abscission layer or separation layer is appropriately used or should be used at all. A majority of the workers in this field maintain its use but others (77) suggested that use of this term should be stopped. They pointed out 
that the cells resulting from secondary cell division characteristically occurring in the abscission zone constitute the abscission layer. They noted, however, that this secondary cell division does not always occur and so no abscission layer may form although abscission can take place. Addicott and Lynch (8) and Barnell (19) agreed that while secondary cell division may take place, it is not an essential prerequisite of abscission.

Abscission of Flowers and Fruits

The extensive abscission of flowers and/or the premature abscission of their parts play significant roles in the perpetuation of the plants bearing them. Often, these are important considerations on whether or not such crops will be cultivated commercially.

Heavy shedding of flowers has been observed in a number of economic crops, including cotton (53, 54); muskmelon (98); sweet pea $(71,121,153)$; soybean $(163,171)$; tobacco (99, $182,183,184)$; and apples (44).

In citrus, only a few of the flowers develop into fruits. Most of them are shed about the time the petals fall or soon after (151). They are abscised with the formation of an abscission layer either at the base of the ovary or that of the pedicel. In Iemon, 52\% of the flowers dropped before they could set (21) while more than $1 / 3$ of 'Shamouti' orange flowers shed before anthesis and a total of $55 \%$ dropped before the fruit-set stage (151). About 65\% of the 'Washington' navel orange flowers dropped before opening but only $39 \%$ of 'Valencia' flowers abscised before the fruit-set period (21). 
The abscission of the style before the pollen tubes enter the ovary accounts for self-incompatibility and unfruitfulness in some crops. This had been demonstrated in petunia (185, 186); lily (64); cherry and plum (110); and apple (44). Pollen tubes in self-incompatible 'Orlando' tangelo also failed to enter the ovary $(32,83,167)$ but whether or not this was due to the development of an abscission layer at the base of the style prior to the time the pollen tube reached that point was not determined.

Pre-mature fruit abscission is widespread among many cultivated crops. It constitutes a significant problem in apples $(60,61)$; cherry and plum (110); and cotton (53, 124, 183, 184).

In citrus, the period of accelerated fruit drop in the early summer months is referred to as "June Drop" although it does not necessarily occur in June. This has been a serious problem, especially among some seedless varieties (38, $40,81,84)$.

\section{Morphological Aspects of Abscission}

The abscission zone

The development of an abscission layer is initiated in the ground tissue of the abscission zone (68). The vascular bundles are usually broken mechanically at the end of the separation process $(105,113)$. In some cases, tyloses may appear in the tracheary elements before or soon after the break occurs (68).

Before abscission is initiated, an abscission zone assumes 
varying characteristics peculiar to the plant and plant part in which it is found. Petioles of Quercus palustris and $\underline{Q}$. coccinea (86) do not have well-defined abscission zones. The cells at the bases of their petioles and pedicels also appear to be histologically the same as those of adjacent tissues. No antecedent structural indication of the position of the abscission zone was likewise observed in Mirabilis jalapa but evidences of physiological activity were found in a layer of cells (113). The same findings were observed in the floral parts.

The abscission zone is generally prominent in plants. Barnell (19) showed that the abscission zone is predetermined both morphologically and anatomically in the pedicels of mango and avocado fruits. It is also preformed in both the petiole (85) and pedicel (38) of citrus and consists of 10-18 and 10-20 tiers or cells, respectively. Only 10-20 rows of cells were found at the pedicel of cotton flowers (54).

Eames and MacDaniels (55) described the abscission zone of a mature leaf as having vascular bundles which are reduced in diameter; sclerenchymatous tissues were weak or absent; collenchyma tissues were lacking; and some of the parenchyma cells had denser cytoplasm than those of other parts of the petiole. Earlier MacDaniels (119) showed that the abscission zones in normal pedicels of apple flowers and young fruits were characterized by the presence of abundant specialized collenchyma and reduction in amount or absence of sclerenchyma cells in the cortical region. The cells in the abscission 
zone of Fraxinus americana leaf were smaller and their protoplasm was denser than those of surrounding tissues (70). They were potentially active meristematic parenchyma cells with middle lamellae and primary walls (70). Those in citrus leaves and fruits were also small, isodiametric in shape, and had dense protoplasmic contents $(38,85)$. In addition, no intercellular spaces were observed at the abscission zone of fruit pedicels.

The middle lamellae of parenchyma cells in the abscission zone are pectic in nature, consisting of insoluble pectates and free of cellulose (70). Large amounts of starch are stored in this zone before the initiation of abscission sets in (54).

\section{Methods of abscission}

There are 3 types or processes of dissolution phenomena which bring about the abscission of flowers, leaves, fruits, and stems. The first type consists of the dissolution of the middle lamellae of the cells in the separation layer $(8,30,45,68,70,99,125,183)$. This type is the most widespread and it is called the common type or usual method of abscission. The second type is characterized by the complete digestion of the primary and secondary cell walls of the separation cells, leaving the protoplast invested by a tertiary membrane $(8,68,113)$. In the third type, entire cells or layer of cells are dissolved $(8,68)$.

The process of abscission in citrus leaves conforms to the usual type, involving the separation of the cells along 
the plane of the middle lamellae $(85,147)$. No cell division or elongation had been observed during the process. The same type was found in the abscission of citrus fruits (38, 179) but in addition, cell walls of other cells were also dissolved together with the middle lamellae.

\section{Physiology of Abscission}

Extensive reviews on the physiology of abscission are available $(8,22,106)$. However, since the objective of the research conducted is not physiological in nature, only a brief review of the literature on the physiology of abscission is included.

Addicott, Lynch, and Carns (9) enumerated some of the concepts associated with or underlying abscission. Basically, these can be grouped into the auxin gradient theory $(6,9,7,23$ $65,53,87,88,89,90,91,92,104,128,152,144)$; auxin concentration theory $(18,131,146)$; time of auxin application concept (145); auxin-senescence factor theory (10, 11, 46, $47,89,92,137,138)$; auxin-ethylene balance theory ( 3,4 , $77,80,143)$; mobilization of metabolites concept (49, 130, 148, 149); anti-oxidant hypothesis $(12,34,153,165)$;

carbohydrate-nitrogen balance concept (8, 59, 153); and others (164).

Currently, the most popular of these concepts is the auxin-ethylene theory.

\section{Factors Influencing Abscission}

The abscission of a plant organ may be either accelerated, delayed, or prevented. Thus, agencies influencing abscission 
may be classified into either abscission promoting or delaying.

Natural factors which have been shown to influence abscission of plant organs include temperature (40); moisture relations (100, 163, 187); mineral nutrition (8, 151); damage from insects and diseases $(21,53,75,78)$; and mechanical injuries (21).

Growth regulators such as the auxins (78, 22, 24, 31, $35,36,48,52)$; cytokinins (37, 138); gibberellins (5, 40, $41,50,51,96)$; and abscisins or dormins $(6,107,132,133)$ may influence abscission. The first 3 have been demonstrated to exhibit 2-phase actions, promoting abscission at one concentration and delaying abscission at another (25, 26, 33, $106,158,160,161)$.

Gibberellic acid has been shown to accelerate cellular division in the abscission zone of cotton leaf, resulting in the formation of the abscission layer (26). Furthermore, final separation subsequent to GA treatment was brought about by schizogenous breakdown of the middle lamellae of both the anti- and periclinal cell walls.

Gibberellins have been shown to be active abscissionpromoting agents for cotton leaves and fruits (5, 25, 26, 33); tomato and bean leaves (5, 22, 37); and young fruits of apple (51). However, they have also been successfully used to control fruit drop in pears (79), tomatoes (97, 181), and cotton (5). Parthenocarpic fruit development in apples was likewise induced with GA sprays (50). 
In citrus, gross morphological changes due to GA have also been demonstrated. Potassium-gibberellate (KGA) sprays in California resulted in the production of fruits with thicker and greener rinds when applied at various stages of flowering and early fruit set in 'Washington' navel orange (84). The same effects were noted in 'Valencia' (43), grapefruit (42), and lemon (41) with concentrations ranging from 37.5 to 300 ppm applied to whole trees past the full bloom stage.

Smaller and elongate fruits were observed with 100 to $500 \mathrm{ppm}$ of the same material on self-pollinated but not on crosspollinated 'Clementine' mandarins (157).

GA sprays may either promote or delay the abscission of a citrus organ. In California, similar concentrations (37.5 to $300 \mathrm{ppm}$ ) of KGA applied at past full bloom stage on lemons (41), grapefruit (42), and 'Valencia' oranges (43) increased leaf and fruit abscission. In 'Washington' navel, twig-die-back, severe leaf drop, and lower fruit set resulted from whole-tree spraying with 46 to 184 ppm of KGA at 4 dates during flowering and early fruit set (84). These adverse effects were even more pronounced when the plants were sprayed with the material near the spring growth-flush stage.

In Florida, on the other hand, whole-tree sprays ranging from 10 to $100 \mathrm{ppm}$ of $\mathrm{KGA}$ on navel and 10 to $200 \mathrm{ppm}$ on 'Valencia' oranges did not affect yield nor produce any adverse effects on the trees (102). However, fruit set was significantly increased when only flowering shoots were treated with the same material.

In 'Clementine' mandarin, lower concentration of KGA 
did not influence the trees (157). However, higher concentrations of the same spray material increased fruit set, reduced fruit size, and damaged the trees. In the same experiment, application of KGA or GA to individual flowers significantly increased the set of self-pollinated fruits but not the crosspollinated ones.

The responses of 'Orlando' tangelo to GA sometimes varied with tree condition when a high concentration was used (102). In 3 separate orchards, a concentration of 50 ppm resulted in (1) increased yields of normal fruits; heavy splitting, coarse green fruits, and thickened stems; and (3) coarse, green extremely undersized but otherwise increased yields of normal fruits.

Other evidences of the influence of tree condition in the response to GA was shown by heavy leaf drop of 'Orlando' leaves when applications were made in full bloom as opposed to no leaf drop in similar and higher concentrations in post bloom. Moreover, in California, severe damage resulted in applications of GA to navel orange trees in full bloom (84) while no damage or increased yield was found at even very high concentrations in Florida (102).

Also, varieties differ greatly in their sensitivity to GA. 'Orlando' tangelos are very responsive to whole tree sprays of 5 to $15 \mathrm{ppm}$ GA while 'Dream' navel and 'Valencia' have not responded to these and much higher concentrations (102).

One unexplained response is the large increase in yield of some citrus varieties when single flowers or flowering 
shoots are treated as opposed to no increase when whole trees are sprayed with similar, higher, and lower concentrations (102).

Thus, a number of fruits, particularly citrus, have been responsive to GA but the responses have often varied and little is known as to the precise cause of these variations.

\section{External Fruit Parameters and Seed Development}

During the past 2 decades, it had been shown that there is a relationship between concentration of hormones in the fruit and development of the seed. Two peaks in the concentration of a hormone, each coinciding with specific stages of endosperm development and reduction of fruit drop, were reported in apples $(117,118)$. The first period of active hormone production took place 3 to 4 weeks after petal fall at which time nuclear endosperm development was active (117). The second period was reached when the endosperm became cellular (118). 'June Drop' in apple, which was preceded by the second peak of hormone production (118), occurred when the embryos were of the globular stage (188).

However, laboratory techniques for determining the physiological $(81,180)$ and morphological (83, 166) conditions of the fruit and seed are cumbersome. External parameters which may be used to estimate these physiological and morphological conditions have been sought. In peach (115) and cherry (116), it was shown that the abscission of the style coincided with the beginning of embryo enlargement. Furthermore, it was shown that in peaches, the cytokinetic stage 
of the endosperm at which certain chemical sprays are most effective for fruit thinning (114), was consistently and closely related to a specific stage of fruit development (108). While there have been fairly extensive studies of the morphology $(15,17,20,72)$ and physiology $(81,180)$ of young citrus fruits, gross morphological characteristics of the flower and fruit, which may reflect the condition of the seed, have not been determined. 


\section{MATERIALS AND METHOD}

\section{Plant Materials}

All work was conducted on the self-incompatible 'Orlando' tangelo on 'Cleopatra' mandarin rootstock, which typifies the tangerine-grapefruit hybrids that are self-incompatible and erratically fruitful.

The trees varied from 5 to 6 years of age, an age at which a vigorous growing 'Orlando' flowers heavily, has a good crop potential, but is often unfmitful.

All trees were sufficiently isolated to largely mue out cross-pollination with other varieties.

In 1967, part of the trees were located near Plymouth, Florida and some at the University of Florida, Gainesville. In 1968, all work was conducted at Gainesville.

In all cases, the trees were in excellent condition and were irrigated so that water stress was not a problem. In 1968, the bloom period was 3 weeks later than in 1967. This was caused by prolonged cool weather during late winter and early spring.

\section{Procedures}

\section{Field Techniques}

All flowers which were to be self-pollinated, cross-pollinated, unpollinated or treated with GA were emasulated and depetaled just prior to anthesis, except where bud-pollination 
studies were conducted. In the latter case flowers were emasculated and self-pollinated 2 days prior to anthesis.

Self- and cross-pollinations were made by brushing the stigmatic surface of 'Orlando' pistils with open stamens of the appropriate variety. Flowers used as the pollen source were collected prior to anthesis and matured free of contamination. 'Parson Brown' sweet orange was used as the pollen source for cross-pollinations.

GA was applied by dipping the pistils in a 500 ppm solution.

All flowers used for the comparative studies were pollinated or treated within a 4-hour period. Flowers used in general seed development studies were tagged over a period of 1 week during full bloom and labeled so that the time elapsing from pollination to collection could always be determined.

\section{Laboratory Techniques}

Pistils, young fruits, and seeds were killed and fixed in FAA solution. They were trimmed along 2 sides and aspirated for 10 hours. They were dehydrated with tertiary butyl alcohol and embedded in paraplast.

The samples were sectioned at 5 to 25 microns with a microtome.

The safranin-fast green staining procedure as outlined by Jensen (93) and Johansen (94) was followed in studying the anatomy of the abscission layers and seeds. Pollen tube growth was traced following both a squash technique developed 
for citrus $(83,166,167)$ and sectioned pistils (32). In both cases callose plugs of the pollen tubes were stained with Lacmoid-Martius yellow.

\section{Experimental Design}

\section{Pollen Tube Growth and Seed Development}

Following pollination, sets of 20 pistils each were collected at random at 2-day intervals through the $14^{\text {th }}$ day. Thereafter, 20 samples were collected at 5-day intervals through 140 days after pollination (30 days after first seed germination).

Fruit volume was obtained at each date of collection. Gross observations were made of color changes of the styles and pistils and of style and ovary abscission.

Microscopic observations were made of the development of the abscission layers in the style, ovary, and pedicel; growth of the pollen tubes; embryo and endosperm development; and seed formation for each appropriate sampling date.

The relation to fruiting of gross morphological changes, abscission, pollen tube growth, and embryo, endosperm, and seed development were determined.

Effects of GA and Pollination

Following pollination, 20 pistils each from the following treatments: dipped in GA after self-pollination, selfpollinated, cross-pollinated, bud-pollinated, and pollenexcluded were collected at 2-day interval for 24 days. Pollen tube growth, abscission layer development, color changes of the pistil, and seed development were studied for each date 
of collection. Fruit size and seed content determinations were made from samples taken 140 days after pollination. 


\section{RESULTS}

\section{Growth of the Pollen Tubes}

Both 'Orlando' and 'Parson Brown' pollen germinated equally well on the stigmatic surface of 'Orlando' tangelo pistil (Fig. 1). Germination of 'Orlando' pollen was also good when the pistils were dipped in GA solution after selfpollination and when the pistils were selfed 2 days prior to anthesis.

The polien tubes grew through the stigmatic surface both intercellularly and through the stylar canal openings. Beyond the stigmatic knob, the pollen tubes were confined closely along and mostly inside the canals (Fig. 2). In the ovary wall, all the pollen tubes found were within the ovarian canals which emptied into the locules.

Pollen tubes of the compatible 'Parson Brown' grew down the style at a faster rate than those of selfs made at anthesis, reaching the ovules 10 and 6 days after pollination in 1967 and 1968, respectively, (Table 1; Fig. 3).

From this experiment, the growth rate of pollen tubes from pollinations made prior to anthesis could not be precisely compared with those made at anthesis because of a disparity in style length at pollination time. However, pollen tubes of self-pollinations made prior to anthesis 


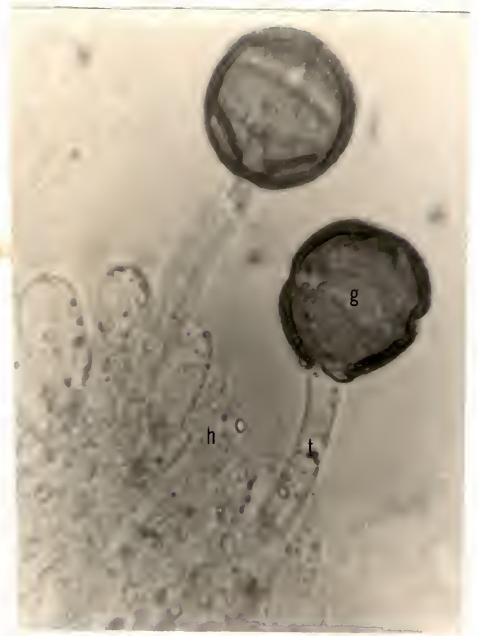

Fig. 1.--Pollen grains of citrus germinating on the stigmatic surface of 'Orlando' tangelo pistil, 20 minutes after pollination. g, pollen grain; $h$, stigmatic hair; $t$, pollen tube $(2700 \mathrm{x})$. 


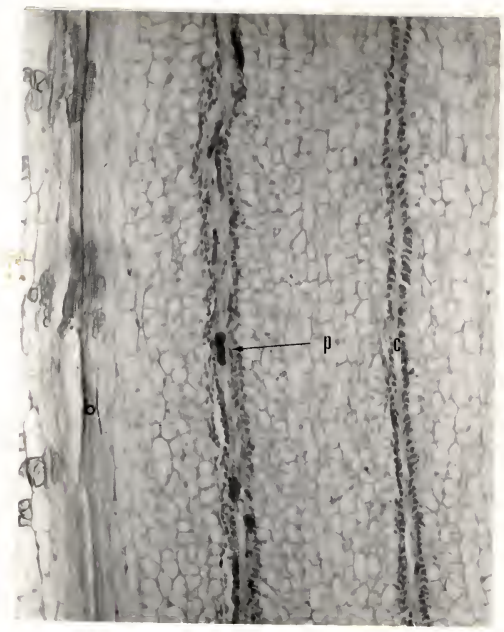

Fig. 2.--Longitudinal section of 'Orlando' tangelo style 2 to 6 days after pollination. c, stylar canal; $p$, callose plugs of the pollen tubes; and $b$, vascular bundle (750 x). 
Table 1.-- Growth of pollen tubes inside the pistil of 'Orlando' tangelo at varigus dates following GAtreatment and pollination-'.

\begin{tabular}{|c|c|c|c|c|}
\hline \multirow{2}{*}{$\begin{array}{l}\text { Days After } \\
\text { Pollination }\end{array}$} & \multicolumn{4}{|c|}{ Type of Pollination } \\
\hline & Self & $\begin{array}{c}\text { Self, } \\
\text { Pre-anthesis }\end{array}$ & Self, GA & Cross \\
\hline
\end{tabular}

1967

\begin{tabular}{|c|c|c|c|c|}
\hline 2 & sty. 1 & Sty. 2 & sty. 1 & Sty. 1 \\
\hline 4 & Sty. 2 & sty. 4 & sty. 2 & Sty. 2 \\
\hline 6 & sty. 3 & Ovary & sty. 3 & Sty. 5 \\
\hline 8 & Sty. 4 & Ovary & Sty. 4 & Ovary \\
\hline 0 & sty. 5 & Ovule & Sty. 5 & Ovule \\
\hline 12 & $-\underline{2} /$ & Ovule & Ovary & Ovule $\underline{2}$ \\
\hline 14 & - & Ovule & Ovule $e^{2 /}$ & Ovule \\
\hline
\end{tabular}

1968

\begin{tabular}{|c|c|c|c|c|}
\hline 2 & Sty. 2 & sty. 3 & sty. 2 & sty. 2 \\
\hline 4 & Sty. 3 & Sty. 5 & Sty. 5 & Ovary \\
\hline 6 & sty. 4 & Ovule & Ovule & Ovule \\
\hline 8 & sty. $5^{\underline{2} /}$ & Ovule & Ovule & Ovule $e^{2 /}$ \\
\hline 10 & - & Ovule $e^{2 /}$ & Ovule & Ovule \\
\hline
\end{tabular}

${ }^{1}$ The style was divided into 6 equal sections, each numbered 1 to 6 starting from the stigmatic end. Numbers in the table indicate which of the sections had been penetrated by the pollen tubes at the date indicated.

${ }^{2}$ More than $90 \%$ of the styles abscised. 


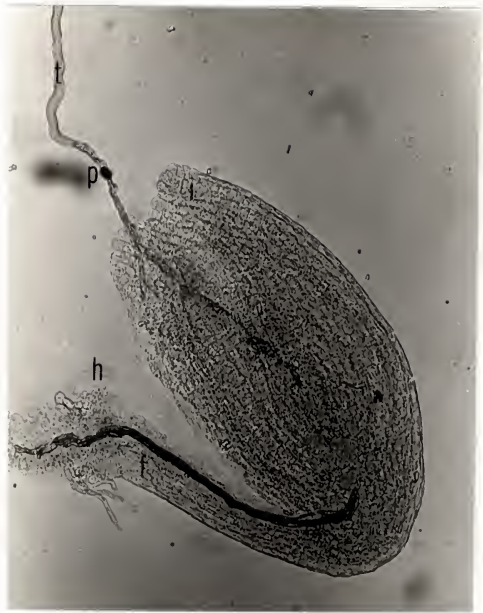

Fig. 3.--Pollen tube inside 'Orlando' tangelo ovule, 6 and 10 days after pollination in 1968 and 1967 , respectively. $t$, pollen tube; $p$, callose plugs of the pollen tube; $i$, integument; $f$, funiculus; $h$, placental hair $(900 \mathrm{X})$. 
penetrated the ovary, reached the ovule, and resulted in seed production while selfs made at anthesis did not.

When pistils were dipped in GA following self-pollination at anthesis, the rate of pollen tube growth varied. They grew at about the same rate as the untreated self-pollinations made at anthesis in 1967 and at approximately the same rate as the compatible pollen tubes in 1968. In both years, however, the pollen tubes penetrated the ovary and reached the micropyle.

\section{Abscission}

\section{Style Abscission}

At an early stage of development, the abscission layer consisted of small and irregularly shaped parenchyma cells (Fig. 4). At more advanced stages, one or more layers of cells proximal to the separation layer elongated (Fig. 5) while the rest of the cells in the abscission layer maintained their early shapes and sizes. Some of the elongated cells also had more than one nucleus.

The number of cells composing an abscission layer varied, ranging from 4 to 8 cells and formed a distinct band across the base of the style that was usually concave or straight.

The abscission layer usually started from the epidermis and progressed towards the inner tissues (Fig. 4). In some cases, it developed from the inner to the outer tissues.

Complete separation or blockage of the stylar canals did not occur until one day prior to abscission (Fig. 5). 


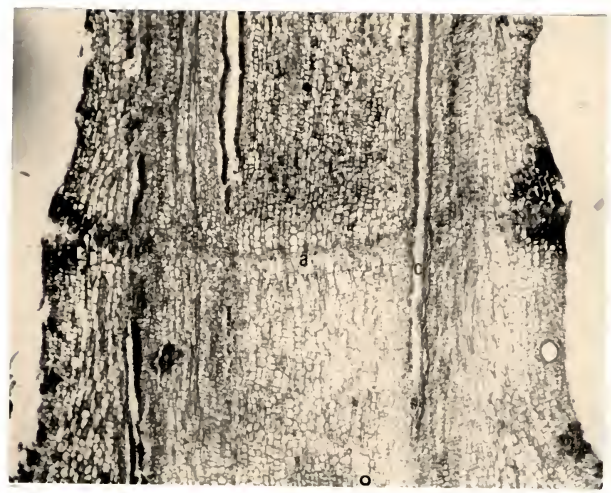

Fig. 4.--Abscission layer at the base of the style of 'Orlando' tangelo pistil, 6 days after full bloom in 1968. a, abscission layer; c, stylar canal; o, ovary $(40 \mathrm{x})$. 


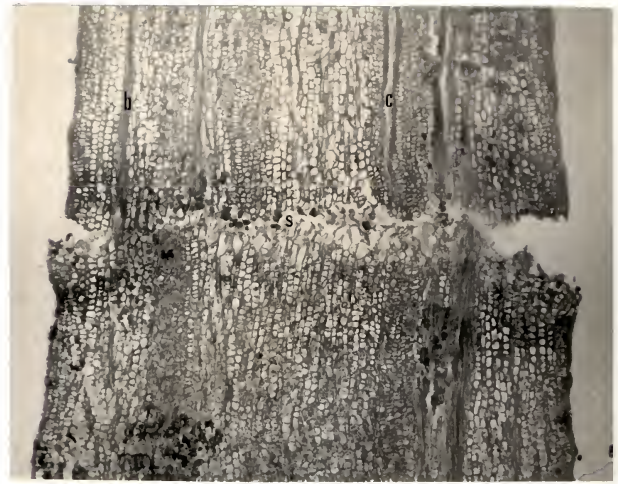

Fig. 5.--Separation layer at the base of the style of 'Orlando' tangelo pistil, 8 days after full bloom in 1968. b, vascular bundle; c, stylar canal; $s$, separation layer; $p$, protective layer (40 X). 
However, evidences of style senescence were noted prior to the time of initiation of abscission. Styles gradually changed from a bright to a dull green (Fig. 6b). The base of the style had turned brown 2 days prior to its separation from the ovary and the entire style was virtually black by the time abscission was completed.

\section{Ovary and Flower Abscission}

\section{Pedicel and inflorescence}

There are 2 abscission zones in the inflorescence, one near the base of the pedicel (Fig. 7) and another at the base of the main axis of the inflorescence (Fig. 8).

Abscission layer formation and separation from the plant were preceded by discoloration of the pedicel or inflorescence axis by about 1 and 3 days, respectively. Also, an exterior notch was noted on the abscission zone at the base of the pedicel during and soon after anthesis. Such notches did not occur at any other location.

The abscission layers developed fairly similar. In both cases, the development of the abscission layer was formed by secondary divisions of parenchyma cells from the epidermis, inward. These cells increased in size until they were finally separated from cells distal to them. The abscission layer consisted of 2 to 5 tiers of cells across the pedicel, forming a concave, sigmoid, or double sigmoid band. At the base of the inflorescence, this layer of cells extended from one leaf-scar or node to another (Fig. 8). In rare cases, the abscission layer cut perpendicularly across the 


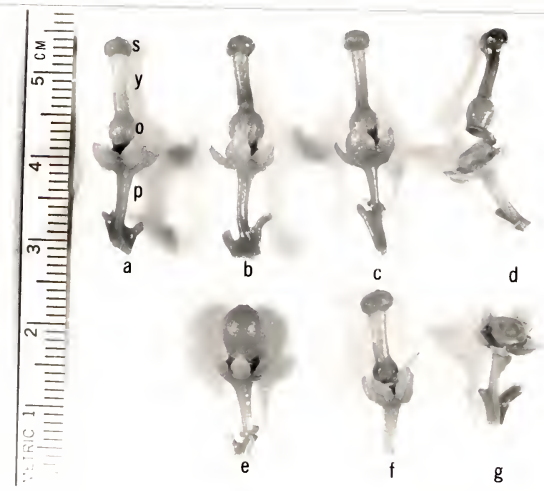

Fig. 6.--Discoloration and abscission of 'Orlando' tangelo styles and pistils. s, stigmatic knob; y, style; $\circ$, ovary; $p$, pedicel; $a$, young normal pistil; $b$, pistil with discolored style; c, discolored pistil; $d$, pistil abscising at the base of the ovary; $e$, pistil with abscised style; f, pistil which abscised at the base of the pedicel; g, receptacle and pedicel after ovary abscission (1.5 X). 


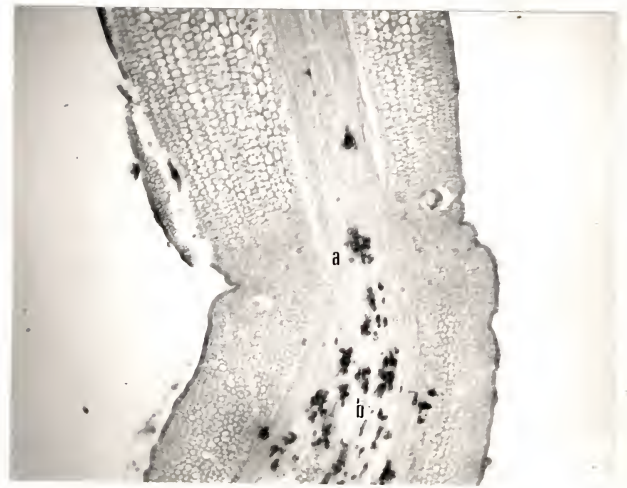

Fig. 7.--Notch at the base of the pedicel at which young flowers before and soon after anthesis abscised. $a$, abscission zone; b, vascular bundles (30 X). 


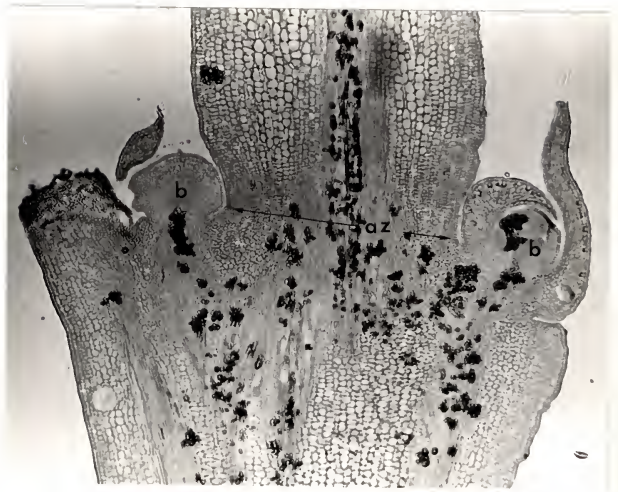

Fig. 8.--Pedicel of 'Orlando' tangelo flower showing the abscission zone, az, between 2 vegetative buds, b. $(25 \mathrm{x})$. 
axis between 2 leaf-scars and did not connect with either scar.

At the base of the pedicel, abscission layer formation was perpendicular to the pedicel axis and at the preformed notch. Virtually all abscission in the inflorescence occurred at this zone, even though another abscission zone was present.

Both GA and pollen reduced abscission of flowers at the base of the pedicel (Table 2). Almost all non-pollinated flowers (90\%) abscised at the base of the pedicel within 10 days. Abscission among flowers which were self-pollinated at and prior to anthesis and cross-pollinated at anthesis was about 40 to $50 \%$. On the other hand, only $10 \%$ of the flowers treated with GA abscised at the pedicel within the same period.

After 14 days, no further abscission occurred at the base of the pedicel. Where abscission did not occur at the notch, the area thickened and the notch disappeared. Ovary abscission

Another abscission zone exists at the base of the ovary (Fig. 6d, g). The anatomy of this abscission zone and the subsequent abscission layer was somewhat similar to that of the style rather than the pedicel. There was no morphological indication of the abscission zone prior to the development of the abscission 1ayer.

Where abscission occurred at the ovary base, a color change in the ovary was also noted. The pistil tumed from dark to yellowish green. Within the first 2 weeks, this 
Table 2.-- Abscission of 'Orlando' tangelo ovaries during the 2 main abscigsion periods as influenced by GA and pollination-.

Point of Abscission

and Treatment

Abscission Period
(Days After Anthesis)

$$
4-14 \quad 40-50
$$

Base of the Pedicel

No Pollination

90

Self, Anthesis

50

Self, Anthesis, GA

10

Self, Pre-anthesis

50

Cross, Anthesis

40

Base of the Ovary

No Pollination

10

Self, Anthesis

43

1.53

Self, Anthesis, GA

52

4.61

Self, Pre-anthesis

37

2. 30

Cross, Anthesis

33

2. 30

1 Percentage values in the table are based on the total number of flowers used. 
color change occurred about 2 days prior to development of the abscission layer and 4-6 days before final separation of the ovary. Later during "June Drop", the change in color was often noticed 2 to 5 days before initiation of abscission and about 5 to 10 days before final separation.

There were 2 main periods of fruit drop, one occurred within the second week and the other, 6 to 7 weeks ( 43 to 50 days) after anthesis (Fig. 9).

During the first 2 weeks, treatments had a pronounced effect on abscission. The remaining $10 \%$ of the non-pollinated flowers abscised during this time (Table 2). About $43 \%$ of those self-pollinated and $33 \%$ of those cross-pollinated at anthesis abscised within this time. On the other hand, 52\% of those flowers treated with GA and $50 \%$ of those self-pollinated prior to anthesis abscised during the same period.

While some ovaries fell during the ensuing days, there was another major period of drop which occurred 43 to 50 days following anthesis. During this period, $1.5 \%$ of those from flowers self-pollinated at anthesis and $2.3 \%$ of those from cross-or bud-pollinated flowers abscised. About $4.6 \%$ of those fruits treated with GA fell during this period of "June Drop".

Except for a few fruits, mainly from the GA-treated flowers, virtually no fruit dropped after this period.

Development of the seed

\section{Initial Stages of Development}

The time of fertilization could only be approximated since syngamy itself was not observed. However, the first 
Fig. 9.--Rate of ovary abscission in 'Orlando' tangelo. Abscission rate is per cent abscission based on the number of available pistils counted in the previous date of collection. a, entrance of pollen tube into the ovule; $b$, initial division of endosperm nucleus; c, division of the zygote; $d$, endosperm turned cellular. 


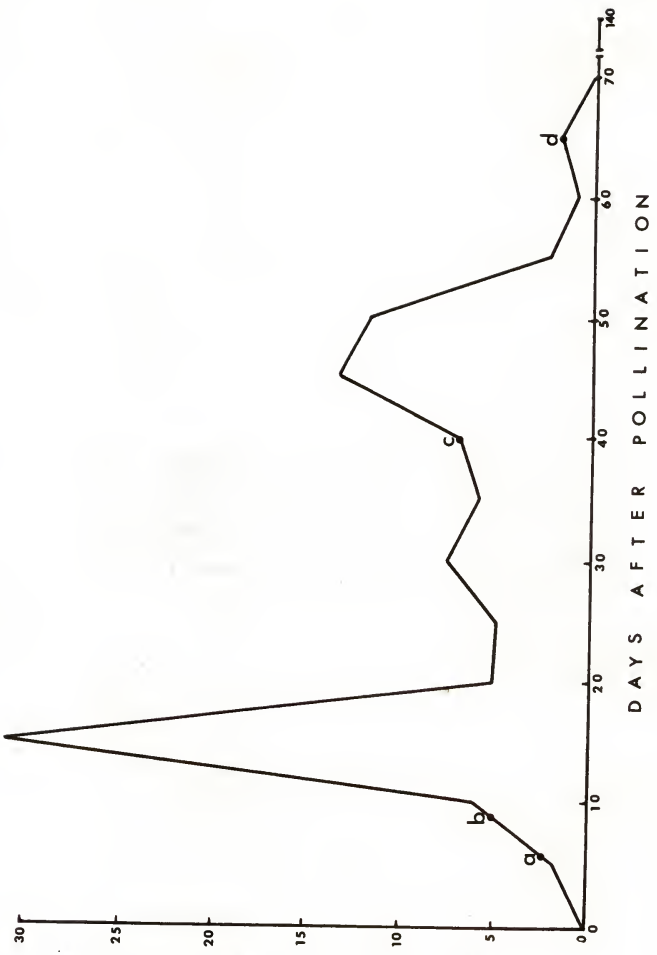

(\%)NOISSIJSa $\forall$ IIn y t 
indication of endosperm development occurred only 2 days after the pollen tube entered the micropyle. Thus, it is reasonable to assume that fertilization took place within 2 days after the pollen tube entered the ovule.

The ovules were plump and somewhat oblong along the micropylar and chalazal ends. This plumpness of the ovule persisted for all cross-pollinated flowers and flowers self-pollinated at pre-anthesis stage. On the other hand, the nucellus of the ovule broke off from the walls of the inner integument and contracted 10 and 14 days after selfpollination at anthesis (Fig. 10, 11) in 1968 and 1967, respectively. This resulted in the formation of a slender mass extending from the chalazal to the micropylar end. At this stage, the megagametophyte was obscured, probably crushed by the shrinkage of the nucellar tissue.

The megagametophytes of ovules in self-pollinated pistils which were treated with GA showed signs of disorganization 10 days after pollination in 1968. Otherwise, they remained morphologically normal until a week later when their nucellar tissues also broke off from the integuments and subsequently contracted.

In general, only one megagametophyte was present in each of the many ovules examined. However, in 2 instances 2 megagametophytes within their respective nucellar tissues were found inside one set of integument (Fig. 12).

\section{Development of the Endosperm}

The first evidence of endosperm development was noted 8 and 12 days after pollination in 1968 and 1967, respectively. 


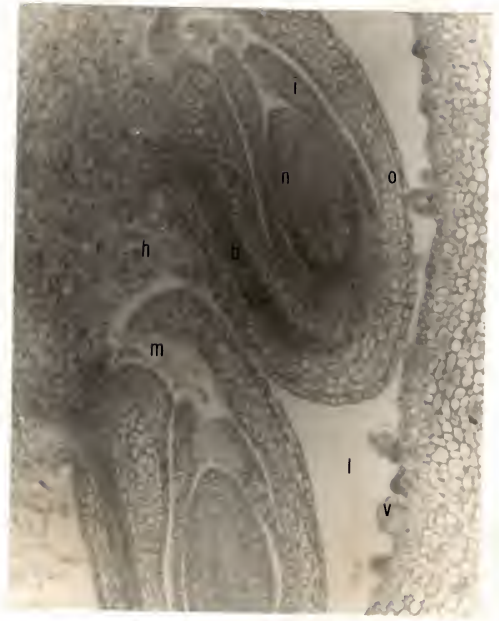

Fig. 10.--Early stage of nucellar contraction indicating lack of sexual fertilization, 10 days after pollination. 0 , outer integument; $i$, inner integument;

$n$, nucellus; $b$, funiculus; $h$, placental hair;

m, micropyle; v, juice emergence; I, locule (900 X). 


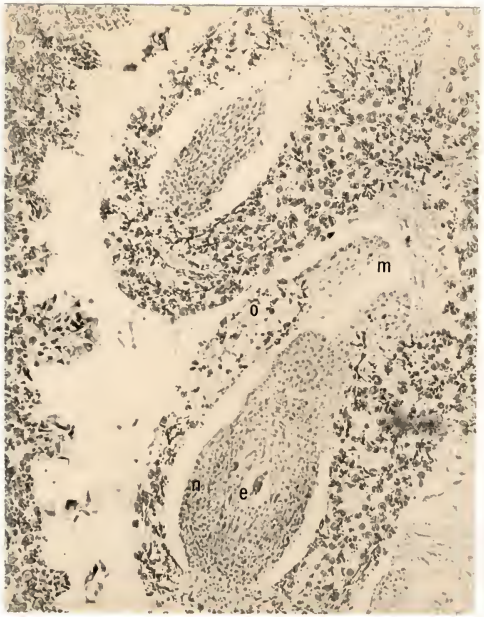

Fig. 11.--Advanced stage of nucellar contraction in 'Orlando' tangelo indicating lack of sexual fertilization, 14 days after polinnation. $m$, micropyle; o, outer integument; $n$, nucellus; e, embryo $\operatorname{sac}(600 \mathrm{x})$. 


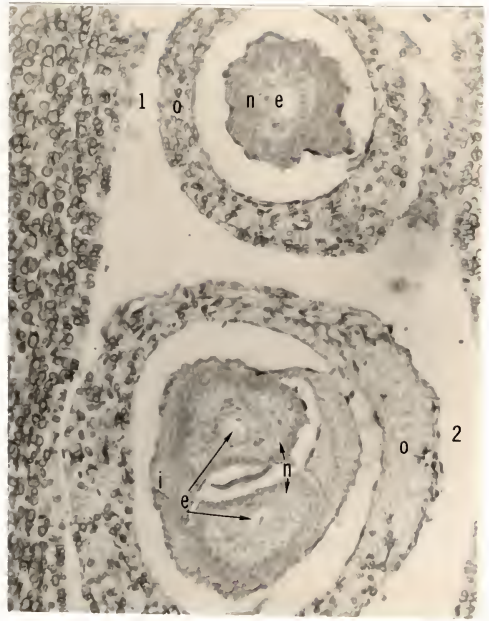

Fig. 12.--Cross-section of 'Orlando' tangelo ovules in advanced stage of nucellar contraction, 14 days after pollination. 0 , outer integument; $i$, inner integument; $n$, nucellus; e, embryo sac; 1 , ovule with one nucellus and embryo sac; 2, ovule with 2 nucellar tissues with corresponding embryo sac (900 X). 
This was true for cross-pollinated pistils and pistils which were self-pollinated at the pre-anthesis stage only. No sign of endosperm development was observed among pistils which were not pollinated, self-pollinated at anthesis, or soaked in GA solution after self-pollination at anthesis.

The endosperm was of the free-nuclear type at early stages of development (Fig. 13, 14). The nuclei were suspended in a tubular mass or a peripheral layer of cytoplasm-like material extending from the micropylar to the chalazal end of the embryo sac. This free-nuclear nature of the endosperm persisted about 65 days after anthesis (Table 3). At this stage, the endosperm became cellular, having 3 tiers of cells on the micropylar end and a layer of cells further down the chalazal end (Fig. 15).

Cells continued to develop toward the inner wall of the endosperm until only a small cavity in the middle remained 80 days after pollination (Fig. 16).

As the embryo developed, the endosperm was absorbed and by 100 days after pollination, it had been completely dissolved. Development of the Embryos

The zygotic embryo

The zygote remained single-celled and mononucleated for several weeks after fertilization (Fig. 13, 17). The first sign of zygotic division was observed 40 days after pollination (Fig. 18). As in earlier stages, it was still one-celled but it had become binucleated. Karyokinesis, but not cytokinesis, had taken place. A 4-celled suspensor, still without a distinct proembryo, was observed within 5 days later. 


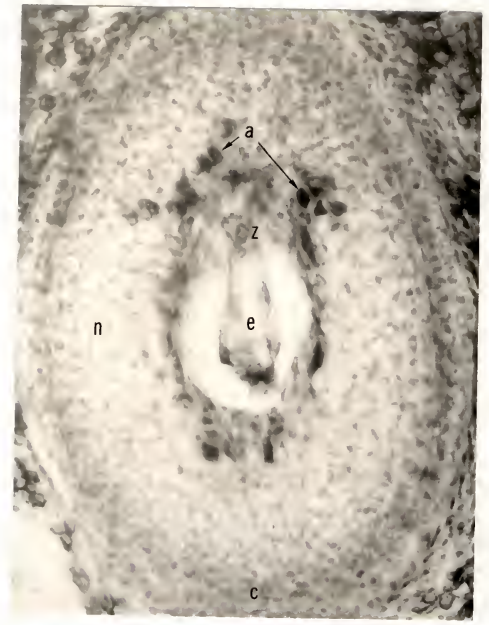

Fig. 13.--Undivided zygote and multinucleate endosperm of 'Orlando' tangelo 14 days after pollination. a, active nucellar cells; $z$, zygote; e, nuclear endosperm; $n$, nucellus; $c$, chalazal end (300 x). 
$|$,

$n$

e
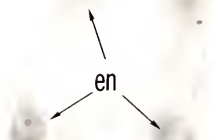

S

Fig. 14.--Undivided zygote and multinucleate endosperm of 'Orlando' tange1o, 14 days after pollination. This stage persisted from 8 through 40 days after pollination. $n$, nucellus; $m$, micropylar end; $z$, zygote; e, endosperm; en, endosperm nuclei; s, embryo sac (900 X). 
Table 3.-- Time from pollination to specific stages of development of the pistil, fruit, and seed in crosspollinated flowers of 'Orlando' tangelo.

\begin{tabular}{lcc}
\hline Stage of Development & 1967 & 1968 \\
\hline & $\frac{\text { day }}{8}$ & $\frac{\text { day }}{\text { Discoloration of the style }}$ \\
$\begin{array}{l}\text { Entrance of the pollen tube into the } \\
\text { ovule }\end{array}$ & 10 & 6 \\
Abscission of the style & 12 & 6 \\
Division of the endosperm & 12 & 8 \\
Division of the zygote & - & 8 \\
Peak of fruit drop & - & $40-45$ \\
Start of rapid-fruit-growth stage & - & $43-50$ \\
Endosperm turned cellular & - & 40 \\
Endosperm fully developed. & - & 65 \\
Endosperm completely absorbed & - & 85 \\
Embryo fully developed & - & 100 \\
Start of diminishing rate of growth & - & 100 \\
Seeds germinated & - & 110 \\
\hline
\end{tabular}

${ }^{1}$ Also called Cell Enlargement Stage (16). 


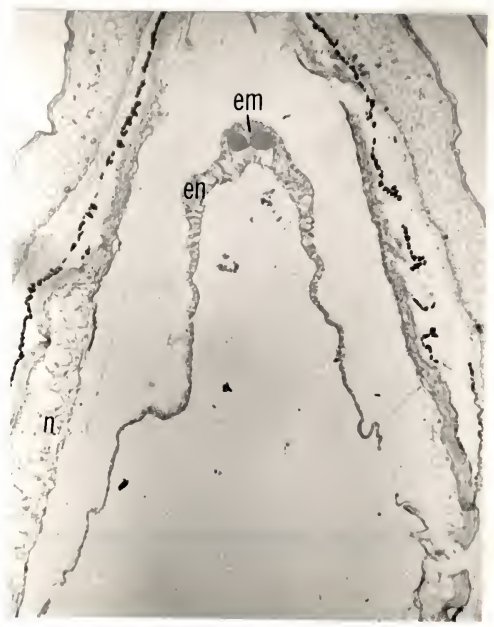

Fig. 15.--Longitudinal section of 'Orlando' tangelo seed 65 days after pollination. em, embryos; en, endosperm; $n$, nucellus (300 X). 


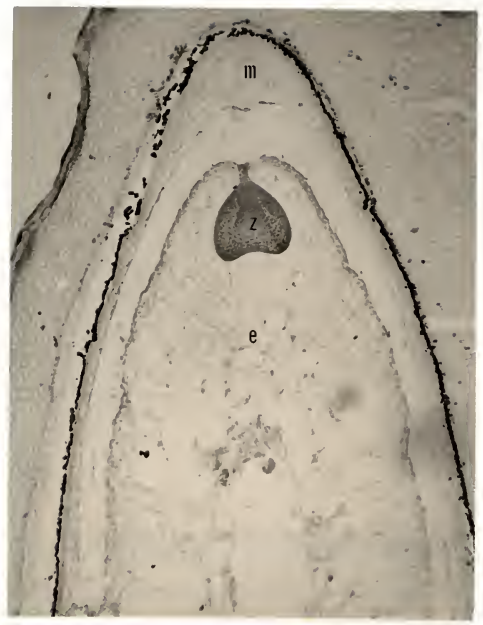

Fig. 16.--Sexual embryo and cellular endosperm of 'Orlando' tangelo, 80 days after pollination on 10 weeks after stylar abscission. $m$, micropylar end; $z$, sexual embryo; $e$, cellular endosperm (900 X). 


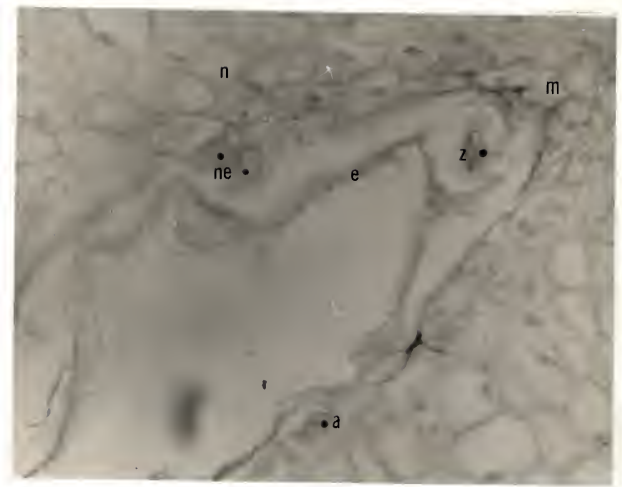

Fig. 17.--Undivided zygote and nucellar embryo of 'Orlando' tangelo, 40 days after pollination or 5 weeks after stylar abscission. $m$, micropylar end; $z$, zygote; $e$, endosperm; $n$, nucellus; a, active nucellar cell; ne, 2-celled embryoid (900 x). 


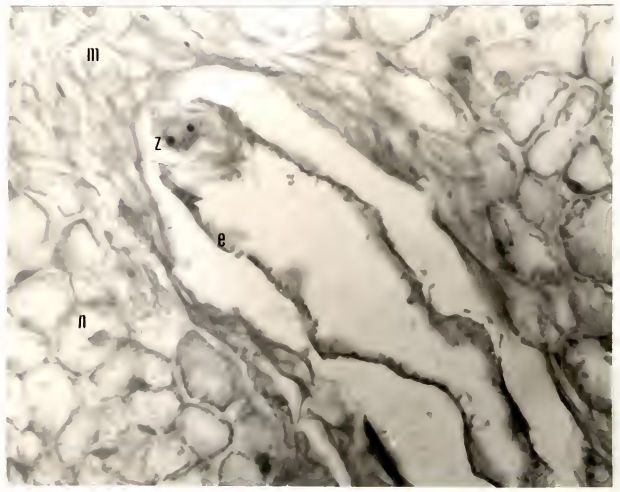

Fig. 18.--Binucleated zygote of 'Orlando' tangelo, 40 days after pollination or 5 weeks after stylar abscission. $z$, zygote; $e$, endosperm; $n$, nucellus (900 X). 
The proembryo was multicellular and its terminal end rounded 50 days after pollination (Fig. 19, 20).

The sexual embryo was characterized by its thin suspensor and its unique location at the micropylar tip of the endosperm (Fig. 21, 22). Its terminal end flattened at about 65 days after pollination. A fork-like embryo developed with the differentiation of the cotyledons 12 weeks after pollination (Fig. 21).

\section{Nucellar Embryos}

Active divisions of some cells in the nucellus started at the same time that the endosperm nucleus commenced development (Fig. 13). However, the protmusion of these embryoids from the nucellus into the nuclear endosperm took place 5 to 6 weeks after fertilization (Fig. 17). They were embedded in the endosperm and finally broke off from the nucellus about 9 weeks after stylar abscission.

Most of the vegetative embryos developed from within the micropylar end of the nucellus, crowding out the zygotic embryo. In a few cases, they were also found beyond the middle half toward the chalazal end.

The nucellar embryos also had suspensor-like structures which broke off at the basal end as the embryoids separated from the nucellus. This body was relatively thicker than that of the sexual embryo, being 4 or more tiers of cells in diameter.

Vegetative embryos in 'Orlando' generally grew faster and were therefore larger than the zygotic embryos. When 2 or more vegetative embryos developed about a sexual one, 


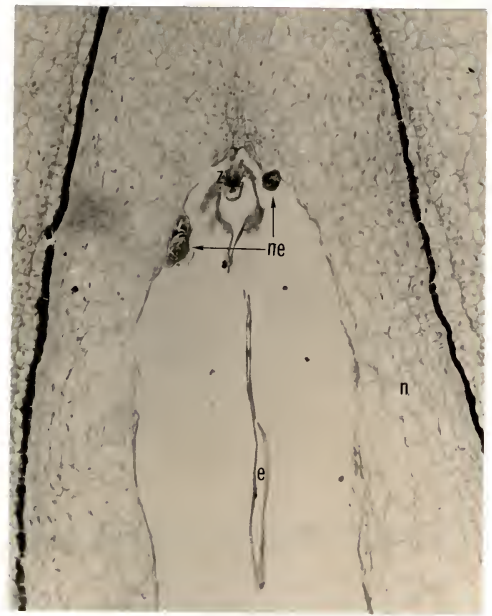

Fig. 19.--Young embryos of 'Orlando' tangelo, 50 days after pollination or 42 days after stylar abscission. $z$, sexual embryo; ne, nucellar embryos; $e$, endosperm; $n$, nucellus (900 X). 


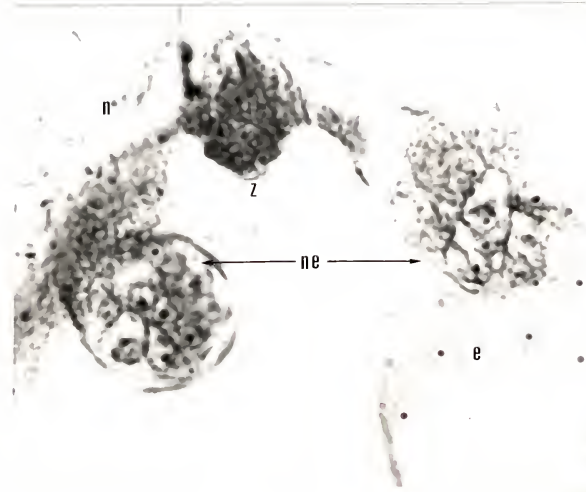

H.H. 20.--Young embryos of 'Orlando' tangelo, 50 days after pollination or 42 days after stylar abscission. $n$, nucellus; $z$, sexual embryo; ne, nucellar embryos; e, endosperm (2700 X). 


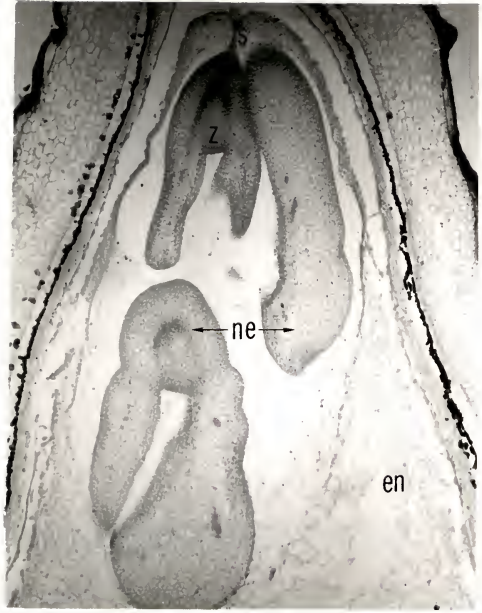

Fig. 21.--Sexual and nucellar embryos in 'Orlando' tangelo seed 85 days after pollination. $z$, sexual embryo; s, suspensor; ne, nucellar embryos; en, endosperm (300 X). 


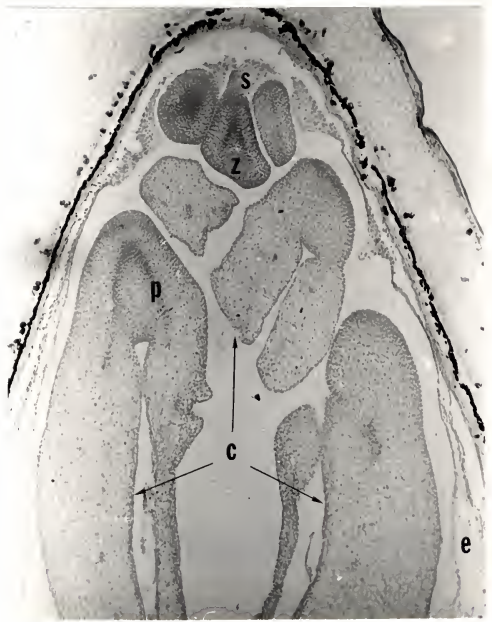

Fig. 22.--Zygotic and nucellar embryos in 'Orlando' tangelo, 90 days after full bloom (12 weeks after abscission of the style). $z$, zygotic embryo; s, suspensor; p, procambium; e, endosperm; c, cotyledons of nucellar embryos (300 X). 
growth of the latter was usually suppressed as evidenced by its reduced size and the twisting of its cotyledons. In many cases, the sexual embryo did not even develop cotyledons (Fig. 22).

\section{Seed Germination}

Seeds had sufficiently matured 110 days after pollination, as shown by germination tests. These seeds were germinated on moistened filter papers after the seed coats had been removed. When seed coats were left intact, the seeds molded and rotted before they could germinate. When seeds of this age were dried under room conditions, they shrank and shriveled badly within 2 days. Similar responses were obtained with seeds collected 30 days later.

\section{Fruit Development}

\section{Fruit growth}

Following pollination, 'Orlando' tangelo fruits increased in volume at an increasing rate for approximately 100 days. However, the fruit enlarged very slowly for the first 40 days. The ensuing period was characterized by a faster rate of growth (Fig. 23). This period of fast and increasing rate of growth lasted about 60 days, after which the fruit enlarged at a slower rate.

The growth curve of the 'Orlando'fruit within the duration of the study contained the first, second, and early phase of the third stages of a simple sigmoid curve.

The rate of growth of the fruit, expressed as the per cent of increase in volume within specific periods in the 
Fig. 23.--Growth curve of 'Orlando' tangelo fmuit with corresponding stages floral abscission and seed development. a, discoloration of the style and fertilization; b, stylar abscission and initial division of the endosperm nucleus; $c$, initial division of zygote and nucellar embryos; second peak in fruit abscission; $d$, endosperm turned cellular, embryo globular; e, embryo heart-shape; $f$, embryo fully developed, endosperm completely absorbed; $g$, seeds germinated. 


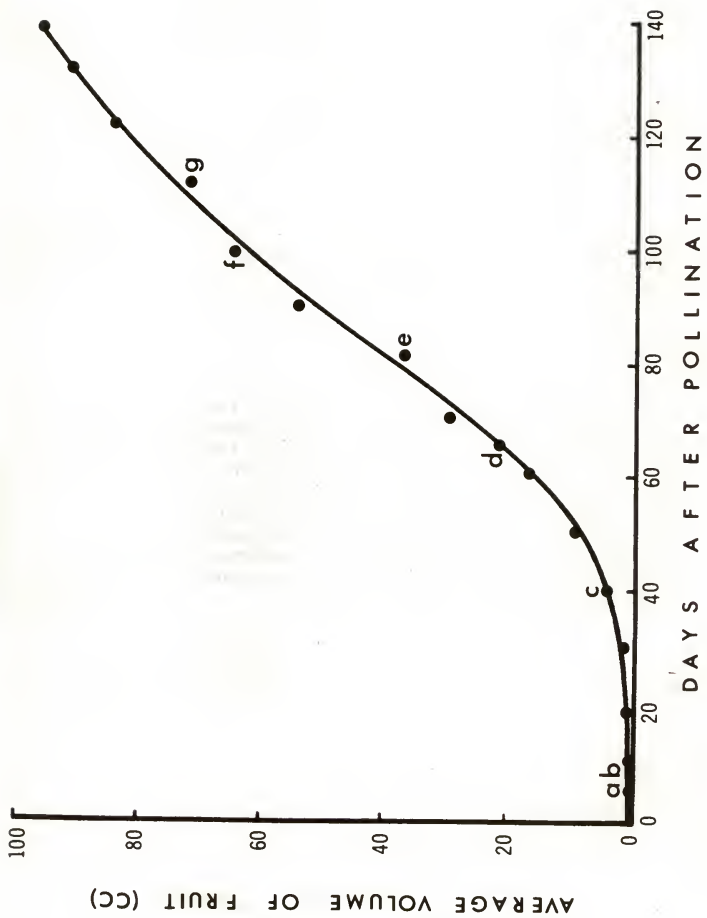


curve, followed a different pattern. Figure 24 shows 2 peaks in the rate of growth of the fruit. The first occurred 15 days after pollination, at which time the fruit was about twice as big as it was 5 days before. An average fruit, 40 days after bloom, was more than double the size of the same fruit 5 days earlier.

Subsequent growth increments were actually larger but relatively smaller when compared with the volume of the fruits from previous measurements. This is clearly shown by the low portion of the growth increment curve which reflects the diminishing rate of growth of the fruit at later stages of development.

\section{Fruit Set, Fruit Size, and Seeds per Fruit}

In 1967, all pistils were collected for morphological studies within 20 days from pollination. Hence, no data on fruiting were obtained.

In 1968, no fruit from non-and 3 of self-pollinated pistils reached maturity (Table 4). On the other hand, 9 and 13\% of GA-treated and cross-pollinated flowers, respectively, grew to mature fruits. Ten per cent of flowers self-pollinated at pre-anthesis stage developed to maturity.

Within the 3 to 4 weeks after pollination, young fruits from GA-treated flowers appeared the largest. Ultimately, fruits from cross-pollinated flowers and flowers which were self-pollinated at pre-anthesis were the biggest. Pistils which were self-pollinated at anthesis and not dipped in GA solution resulted to the smallest fruits in all stages of 
Fig. 24.--Growth rate of 'Orlando' tangelo fruit. Rate is per cent increase in volume from the last measurement. a, entrance of pollen tube into the ovule; $b$, initial division of endosperm nucleus; $c$, initial division of zygote; $d$, endosperm turned cellular; embryo globular; e, embryo heart-shape; $f$, embryo fully developed, endosperm completely absorbed; g, seed germinated. 


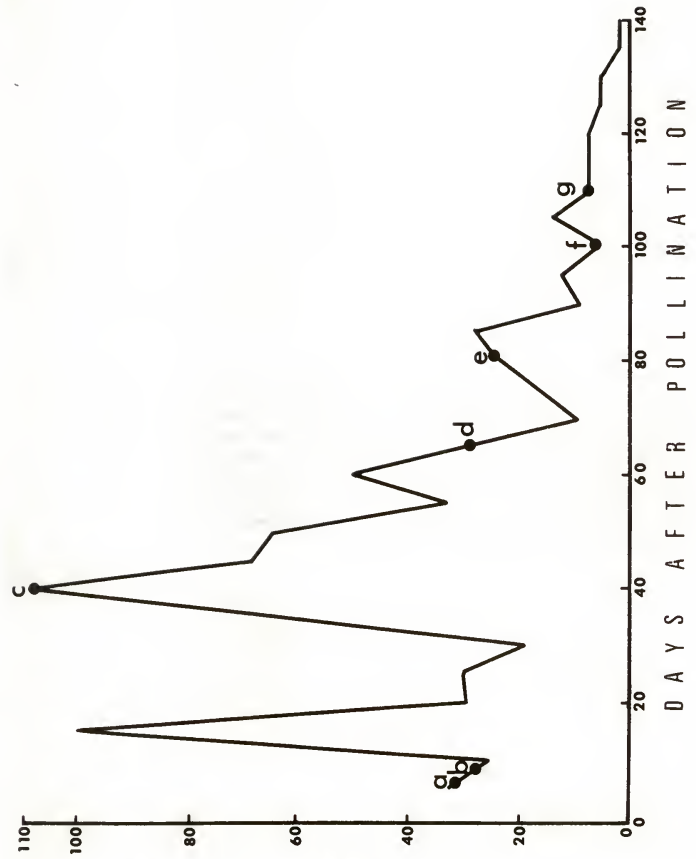

(\%) $\exists \perp \forall y \quad H \perp M O y \cap \perp \perp \cap y\rfloor$ 
Table 4.-- Fruit set, fruit size, and number of seeds per, fruit as influenced by GA-treatment and pollination 1 .

Treatment Fruit Set리 Fruit Size Seed/Fruit

\begin{tabular}{lccc}
\hline & \% & cc & no. \\
No Pollination & 0 & - & - \\
Self, Anthesis & 2.3 & 90 & 0.67 \\
Self, Anthesis, GA & 8.5 & 98 & 0 \\
Self, Pre-anthesis & 10.0 & 108 & 29.1 \\
Cross, Anthesis & 13.1 & 111 & 36.5 \\
\hline
\end{tabular}

${ }^{1}$ Fruits harvested on August 28, 1968.

2 Based on 130 flowers. 
development.

'Orlando' tangelo fruits which developed from flowers cross-pollinated with 'Parson Brown' had an average of 36.5 seeds; the 3 fruits from pistils self-pollinated at anthesis had a total of 2 ; and those from flowers which were self-pollinated at pre-anthesis had an average of 29.1. Fruits from flowers which were dipped in GA solution after selfing did not have any seed. 


\section{DISCUSSION}

\section{Fruit Growth Curves}

In this study, the typical sigmold curve of Bain (16) was found when the volume of the frult was plotted against time (Fig. 23). However, this type of curve does not fully portray the pattern of enlargement of the fruit. In Fig. 24, a curve based on the per cent increase in volume within 5-day intervals is entirely different, with 2 pronounced peaks occurring 15 and 40 days after pollination. This essentially agrees with growth-rate curves reported for 'Washington' navel $(81,180)$, 'Parson Brown' (81), and 'Orlando' (81) fruits. If the sigmoid growth curve alone is used, one would conclude that at 15 and even 40 days after anthesis enlargement was very slight. Actually, fruits were enlarging at very high rates. To obtain the best understanding on fruit enlargement, both viewpoints are needed.

Previous reports for 'Orlando' tangelo indicate 3 peaks in the rate of fruit growth, occurring 8, 25-33, and 48 days after full bloom (81). Three peaks were also shown for 'Washington' navel in 1967 (180) but only the last 2 were noted in 1962 and 1963 (81). 'Parson Brown' fruits, however, had only one growth-rate peak, at 24 days after full bloom (81). 
The first and second peaks in rate of growth in this study coincide approximately with the first and last peaks, respectively, of similar curves for 'Washington' navel (180) and 'Orlando' (81) fruits. The absence of the intermediate peak reported for the above 2 cultivars $(81,180)$ cannot be explained. It may be pertinent, that in the previous studies, growth rates were in terms of fruit diameter, fruit weight, or fruit volume as derived from fruit diameter. Moreover, sampling intervals in these studies were either longer or irregular. The citrus fruit is not a perfect sphere nor does it have a uniform specific gravity during the entire developmental period.

\section{Growth of the Pollen Tube}

Incompatibility systems in plants have been commonly attributed to either the presence of an inhibitory $(13,56$, 126) or the absence of a stimulatory $(78,29,58)$ substance in the pistil. A number of cases in which pollen failed to germinate in the stigma have been reported and attributed to the presence of inhibitory compounds (13, 109, 111). Likewise, observations on pollen tubes being arrested in the style (69) or ovary (123) are not raice.

It has been well established that 'Orlando' tangelo pollen germinates well on its own stigma $(32,83,167)$ and this was true in this study. Thus, incompatibility in this cultivar is not of the type found in potato and radish (111). The only reported study on the pathway of the pollen tube in citrus pistils is that of Banerji (15) who worked with 
Citrus grandis. He reported that the pollen tubes grew only through the canals in the stigma and only intercelluiarly or outside the canals in the style and ovary. However, in this study, the pollen tubes grew both intercellularly and through the canals in the stigmatic knob. In the style, they grew mainly through the canals (Fig. 2) and to a very limited extent, alongside these canals. In the ovary, they grew only in the canals. This was true regardiess of pollen source or treatment.

The rate of pollen tube growth of incompatible and compatible pollen verified previous reports $(83,167)$ in that the latter grew at much faster rate and reached the micropyle within 6 days while the former did not even penetrate the ovary. The rate of growth of pollen tubes in self-pollinations made at pre-anthesis compared well with those of compatible pollinations. This confirms previous reports that self- and cross-pollinations made at preanthesis grew at the same rate and reached the ovules at the same time as those of compatible cross-pollinations (32). In 1968, the 'Orlando' pollen tubes in the GA-treated pistils appeared to have grown faster than in the untreated selfs. Why this occurred in one year and not in another is not known. A number of possibilities exist but all are rather speculative.

\section{Abscission}

The purpose of this research was not to study the precise development of the abscission layers and the process of separation in detail but to carefully record the time of their occurrence and relate this to other phenomena in the 
fruiting process.

\section{Abscission Process}

In all abscission zones (base of style, ovary, inflorescence, and pedicel), the development of the abscission layer, when present, was preceded by a discoloration of the tissue distal to it. In all but the ovary, which turned light green or yellow prior to abscission, the tissues darkened to a brownish color. This indicated the occurrence of rather drastic changes in the physiology of these tissues. On the other hand, the delay in both color change and abscission resulting from GA treatment suggested hormonal control. However, neither the absence of pollen nor pollen source affected either discoloration or separation of the style from the ovary. Pollination treatments resulting in fertilization and subsequent seed formation reduced both discoloration and abscission of the ovary.

There was nothing unique in the morphology of the abscission zones of the parts observed. However, the abscission zones at the base of pedicel and inflorescence differed from those of the style and ovary in having smaller cells which delineated them prior to the development of the abscission layers. Only the presence of the external notch at the base of the pedicel was at all distinctive or unusual in fruit crops.

\section{Abscission of Flowers and Young Fruits}

Since abscission was followed throughout the year only in 1968, this discussion largely relates to that year; however, 
abscission was also recorded periodically for the first 20 days following pollination in 1967 and some comparisons of the 2 seasons are meaningful.

The occurrence of 2 main peaks of abscission in 1968 is in general agreement with other works (81). In the first peak, most of the flowers in non-GA-treated pistils abscised at the pedicel base while virtually none of the GA-treated flowers did. On the other hand, there was a heavy abscission of GA-treated pistils at the base of the ovary during this same period. During the second period of fruit drop, all abscission took place at the base of the ovary, regardless of treatment. This generally agrees with previous reports (38).

From the outset, it was obvious that all treatments delayed abscission as compared to non-pollinated pistils, all of which dropped during the first 2 weeks. Ultimately, more fruits developed from those treatments resulting in seed formation, with GA treatment producing only slightly less. This has also been established in other works (102).

Abscission in 1968 was heavy throughout the season and quite different from that of the first 20 days in 1967 , when there were no abscission regardless of treatment; however, there were no pistils from which pollen had been excluded in that year. This large seasonal difference is not unusual. It has been pointed out previously that in some years most of the young fruits shed shortly after petal fall (181). The reasons for these seasonal differences are not known. 
In this work, it appears pertinent that the bloom in 1968 occurred 3 weeks later than in 1967, being delayed by cool weather, and bursting suddenly into a short period of heavy bloom with the onset of hot weather. Gross observations indicated that vegetative growth was weak and flower pedicels more slender than in previous seasons. Thus, if a growth regulator is to be commercially useful, it must be effective and safe under a wide range of environments. GA appeared to be such a chemical.

\section{Development of the seed}

The development of seeds is well established in great detail for many species of plants. In citrus, there are several reports dealing with certain phases of seed development but all contain gaps. This work covers embryo and endosperm development but not that of the testa.

\section{Fertilization}

Actual syngamy or fertilization of the egg and triple fusion were not seen; however, the pollen tubes entered the micropyle within 6 to 10 days, depending on the season, and free-nuclear endosperm was observed 2 days later. Since it has been reported that syngamy and triple fusion occurred simultaneously in shaddock (17) and that both in shaddock (17) and grapefruit (15) initial division of the endosperm nucleus took place soon afterwards, it is reasonable to fix fertilization on the egg between the time the pollen tubes entered the ovules and initial division of the endosperm nucleus. Bacchi (15) reported that fertilization in grapefruit occurred 4 days after pollination. This agrees fairly well with the 
6 to 10 days reported here. Moreover, Hensz (83) reported that tubes of compatible pollen reached the ovules of 'Orlando' as early as 4 days and as late as 12 days. Thus, seasonal or environmental conditions can be expected to play an appreciable role in determining the time of fertilization. Osawa (136), in Japan, reported that fertilization of satsuma occurred within 30 hours and of $\underline{P}$. trifoliata, 3 to 4 weeks. The latter is a different genus so the difference between it and 'Orlando' is not surprising; however, the very short period of time required for fertilization of satsuma is.

\section{Development of the Endosperm}

As indicated previously, free-nuclear endosperm development occurred 8 to 12 days after pollination and this is in approximate agreement with the findings of Bacchi (15). Others noting endosperm development cite no specific time of its occurrence $(17,136)$.

Cellular endosperms were not noted until 65 days after pollination. Bacchi (15) did not find the cellular endosperm of grapefruit 67 days after pollination at which time his work ceased.

The literature does not contain information on the endosperm in the later stages of seed development in citrus. In this study with 'Orlando' tangelo, the endosperm continued to develop until the entire cavity of the embryo sac was filled. Parts of the endosperm which invested the embryos degenerated, indicating its role as a nutritive tissue 
for the embryos. Within 100 days from anthesis, all of the endosperm had been absorbed.

\section{Development of the Gametic Embryo}

The enlargement of the nucleus of the fertilized egg or zygote was clearly seen by the time of first endosperm division, 2 days after the entrance of the pollen tubes into the ovule. For 32 to 37 days after this time, there were no further visible changes. This long resting stage is characteristic of $\underline{\text { Citrus }}$ and Poncirus. Bacchi (15) reported a resting stage of 50 days for grapefruit and Osawa (136), 21 to 28 days in $\underline{P}$. trifoliata.

The Rutaceae reportedly follows the Ruta Variation of the Onagrad type of embryo development (95). In this type of development, the formation of the octant stage is brought about by the formation of the longitudinal walls in the transversely divided derivatives and by transverse walls in the others. Observations in this study generally follow the same trend of development. However, the work was not sufficiently detailed to be conclusive.

The globular stage as described by Zeller (188) in apples, but not previously in citmus, was observed approximately 57 days after fertilization. In this stage, the developing embryo was composed entirely of meristematic parenchyma cells. The heart-shape stage, also not described previously in citrus but found in other crop plants (188), occurred 72 days after fertilization. This stage was distinguished by the presence of the procambium and the initial indication of 
cotyledon development.

At 92 days after fertilization, the cotyledons were fully differentiated and filled the embryo sac. Seeds collected 10 days later, from which the seed coat was removed, germinated within a week when placed on moist filter paper. When the seed coat was left intact, the seeds did not germinate.

The radicle and plumule were not noticeable at 102 days after fertilization, even though embryos extracted at this date germinated. Moreover, no evidence of radicle or plumule delineation was observed in embryos collected up to 132 days after fertilization. The radicle and plumule of seeds extracted from mature fruits are observable but since observations were carried only up to 132 days after fertilization, about 2 months before fruit maturity, the time of first delineation of the radicle and plumule was not determined.

The lack of radicle and plumule and the failure of seeds to germinate with the testa intact, indicated the seeds were not mature in the fullest sense of the word.

Polyembryony in 'Orlando' tangelo

The development of vegetative embryos from the nucellus is well documented for citrus, although not all varieties produce embryos from the nucellus.

In this work, the first evidence of the development of embryos from the nucellar tissue occurred at approximately the time of the first division of the zygote, 32 to 37 days after fertilization. This was indicated by the enlargement and division of the nuclei and the dense cytoplasm of the 
nucellar cells in the inner wall of the nucellus. Single cells which ultimately developed into embryoids could be distinguished. Soon after the first evidence of development of the nucellar embryos, cell division and organization resulted in multi-celled protruberances into the nuclear endosperm.

The rapidity of development of these embryoids within the seeds varied. Most surpassed that of the gametic embryo while only a few did not. Thus, it was not possible to determine a calendar of developmental stages as was true for the gametic embryo.

The gametic embryo was located at the micropylar tip of the embryo sac but the nucellar embryos were found all around the inner walls of the nucellus. However, the latter developed mainly in the micropylar half.

Previously, it has been reported that one means of distinguishing the gametic from the nucellar embryos was the presence of a suspensor in the former but not in the latter (136). However, in 'Orlando', suspensors, or at least suspensor-like structures, were also found in the nucellar embryos. These structures were wider, thicker, and shorter than that of the gametic embryo. In later stages of development, they disappeared, probably distorted by the growth of the embryo proper.

High rates of nucellar embryo are common in 'Orlando' and most varieties of citrus. There have been some disagreement as to whether sexual fertilization is needed for the induction 
of these embryoids. Johansen (95) stated that nucellar embryony in sour orange and trifoliate orange required fertilization but other species did not. However, he gave no data or references to support this statement. Frost (73) contended that sexual fertilization was needed in citrus and gave supporting evidence. It appears fairly obvious that fertilization of 'Orlando' is needed for nucellar seed development since seeds developed only when compatible pollen was used or when incompatible pollen was applied in the preanthesis stage.

The failure of the sexual embryos to develop and produce seedlings in the great majority of cases may be attributed to several factors, including the larger number of the nucellar embryos, their more rapid growth, and their position in the endosperm.

As many as 10 nucellar embryos were found developing in a single embryo sac and 6 embryoids per sac were common. Rapidly growing nucellar embryos physically blocked the growth of the gametic embryo. The disintegration of the endosperm around the nucellar embryos indicated their utilization of this material and their heavy competition with the gametic embryo for it.

While polyembryony in citrus is primarily from embryos developing in the nucellus, Frost (73) also found fission of the zygote. Bacchi (15) reported the occassional occurrence of more than one megagametophyte within individual embryo sacs of sour orange and grapefruit and Banerji (17) 
reported a similar occurrence in shaddock.

In this work, 2 megagametophytes with their respective nucellar tissues were found within one set of integuments. Neither fission nor 2 megagametophytes within one nucellar tissue were found. However, the rare occurrences of all 3 of these types preclude the conclusion that the type reported here is either limited to or the only one found in 'Orlando'. Interrelationships Between Abscission, Seed Development, and Fruit Development

The need for gross morphological indicators of physiological and internal anatomical developments in the flower, fruit, and seed has been established. This is particularly true where growth regulators must be applied at some specific points in the physiological or morphological development of the flower or seed.

The key points in the sexual process from the time of entry of the pollen tube into the ovule to germination of the seed are indicated along the growth curve of a crosspollinated 'Orlando' tangelo fruit (Fig. 23). Within the lower and first part of the sigmoid curve are indicated the entrance of the pollen tube into the ovule and initial development of the endosperm nucleus. These events coincided with the discoloration and final abscission of the style, respectively. About a week later, the first peak in the rate of abscission and growth of young fruits occurred. A microscopic examination of abscising or abscised fruits revealed no pollen tubes inside the ovary, suggesting that the fruits which abscised were not fertilized. The sudden 
increase in the size of the remaining fruits may be due to their having been fertilized. The production of an auxin after fertilization has been postulated (118).

The resting period of the zygote, lying all along the remaining part of the cell division stage, is characterized by low abscission of the fruits and low rate of growth increment. Zygotes and nucellar cells in division marked the beginning of stage 2 or cell enlargement stage. These events preceded by a few days the second peak in per cent increase in both abscission and growth of fruits. The heavy abscission of young 'Orlando' fruits at this stage of development has been previously reported and attributed to low activity of growth promoters (81). However, the cause for the tremendous increase in the size of the fruit during this period has not been determined.

The transformation of the endosperm from free-nuclear to cellular occurred in the second stage of the sigmoid curve. The last fruit which dropped was observed 5 days after this stage. Growth increment rate was low although the sigmoid curve was going up. This is the same stage of endosperm development when a growth regulator in apple fruits was detected in abundance (118) and the same stage in peach during which NAA sprays were most effective in fruit thinning (114).

Complete endosperm absorption occurred when actual increments in fruit volume started to decrease. At this time, the embryos filled up the entire seed cavity. Seed 
samples collected 10 days later were capable of germination when their seed coats were removed.

No cause-and-effect relationship is implied from the above, only coincidental occurrences. However, possible cause-and-effect relationships are not ruled out.

\section{Self-incompatibility in 'Orlando' Tangelo}

When 'Orlando' tangelo flowers were self-pollinated at anthesis, the pollen tubes did not enter the ovary. Previous workers established this and pointed out the possibility that this may be due to a physical barrier in the form of an abscission layer, which develops prior to the arrival of the pollen tubes at the base of the style (167). Anatomical studies (Fig. 4) showed that the stylar canals were still intact when the pollen tubes of incompatible pollen reached the style base. Hence, there was no physical barrier. However, the abscission layer had begun to develop and deterioration of the style base was underway. This was evidenced by its discoloration well before the incompatible tubes reached that point but after the compatible ones passed through it. This indicates that the canals may play an active rather than a passive role in pollen tube growth, possibly furnishing materials necessary for growth. It has been established that there is a movement of metabolites out of the distal and into the proximal side of the abscission zone as abscission develops (148, 149, 178).

The tubes of incompatible pollen treated with GA passed through the abscission zone and reached the ovule. However, 
there was no seed development. In 1968, the tubes in the GA treatment grew faster than those of incompatible pollen not treated with GA. In 1967, however, the rates of growth of the pollen tubes in both treatments were about equal.

When the incompatible pollen was applied prior to anthesis, it not only reached the ovules but also resulted in seeds even though it did not reach the ovule any sooner than those treated with GA. Thus, the ovule itself is not incompatible with the pollen tubes in selfs. The reason pollen tubes of GA-treated selfs did not result in seeds was not determined. It may be speculated that GA could have resulted in the degeneration of the gametes.

Fertilization and subsequent zygote abortion could have occurred but anatomical studies suggest that this was not the case. In all cases (cross-pollination, self-pollination at pre-anthesis, and GA treatment after self-pollination at anthesis), the ovules appeared morphologically normal when the tubes reached them. However, the nucellar tissues in the GA-treated pistils contracted after a few days. On the other hand, the ovules in pistils which were crosspollinated or selfed at pre-anthesis remained plump and developed into seeds. 


\section{SUMMARY AND CONCLUSION}

\section{Growth of the Pollen Tubes}

Pollen grains of both 'Orlando' and 'Parson Brown' germinated equally well on the stigmatic surface of 'Orlando', irrespective of other treatments. However, only the pollen tubes in cross-pollinated, GA-treated and self-pollinated, and pre-anthesis self-pollinated pistils reached the ovules. The tubes penetrated the stigmatic knob both intercellularly and through the canal openings. Farther down the pistil, they.grew mainly inside the stylar canals and only inside the ovarian canals.

\section{Abscission of Floral Parts}

Four abscission zones along the axis of the flower were found. The abscission zones at the base of the style and ovary were morphologically similar to contiguous tissues before initiation of the abscission layers. However, an exterior notch and smaller cells at the pedicel base and smaller cells at the inflorescence base characterized the abscission zones at the pedicel.

Abscission of the floral parts was always preceded by a change in the color of the abscising organ. In general, final separation was preceded by the development of an abscission layer. Separation was mainly due to weakening of the middle lamellae, followed by dissolutions of cell 
walls in the ground tissue and mechanical breakdown of cells in the vascular bundles.

The time to abscission of the style did not vary with the absence or kind of pollen. However, GA appreciably delayed abscission of the style.

In 1968, most of the flowers which dropped did so within the first 2 weeks after anthesis. This ranged from $62 \%$ abscission among GA-treated to $100 \%$ among nonpollinated pistils. GA treatment prevented abscission at the pedicel and cross-pollination reduced abscission at the ovary base. Subsequent abscissions were all at the base of the ovary, reaching a second peak 43 to 50 days after pollination.

In 1967, no pistil abscised within the first 20 days after anthesis, which demonstrated the large influence of seasonal differences that can exist.

Incompatibility System in 'Orlando' tangelo

The development of the abscission layer at the base of the style and subsequent separation of the style did not present a physical barrier to the growth of incompatible pollen tubes. An active rather than a passive role of the stylar canal in relation to pollen tube growth is speculated.

Self-incompatibility was overcome by self-pollination at pre-anthesis but not by GA treatment of pistils selfpollinated at anthesis. In both cases, the pollen tubes entered the ovules at practically the same time after pollination. The failure of the pollen tubes in the GA 
treatment to cause seed formation was not determined.

Development of the seed

The development of the seeds among cross-pollinated pistils was studied in some detail. Fertilization and triple fusion were fixed at 6 to 8 and 10 to 12 days after pollination in 1968 and 1967, respectively. Initial division of the endosperm nucleus was noticed 8 and 12 days after pollination in 1968 and 1967, respectively. In 1968, the zygote remained inactive up to about 32 and 37 days after fertilization at which time nucellar cells also started to develop into the embryo sac. The endosperm turned cellular 57 days after fertilization and was completely dissolved during the ensuing 35 days. The cotyledons started differentiation 72 days after fertilization. They filled up the entire seed cavity 92 days after fertilization.

The seeds, with seed coats removed, germinated 102 days after fertilization. However, they were not fully developed since their plumules and radicle were not yet differentiated at collection time and did not germinate unless the seed coats were removed.

\section{Development of the Fruit}

When plotted on a volume basis, the growth or enlargement of the fruit followed a sigmoid curve. However, when the relative increases in volume over previous measurements were plotted against time, there were 2 peaks in the rate of growth, one at 15 and another at 40 days after pollination. 
Interrelationships Between Abscission, Seed Development, and Fruit Development

The discoloration of the style coincided with the entrance of the pollen tubes into the ovule. Stylar abscission occurred at about the same time as the initial division of the endosperm nucleus. These events preceded by less than a week the first peak in the per cent increments of both growth and abscission of young fruits. A second peak in fruit abscission occurred 43 to 50 days after pollination. At this time, initial division of the zygote and the second peak in the per cent increase of fruit growth also occurred. This was approximately the transition point between the first and second stage of the sigmoid curve. Cytokinesis of the endosperm occurred 5 days before the last fruit in the "June Drop" period abscised. This was in the second stage of the growth curve, at which time the fruit enlarged at increasing rates. Coincident with the end of the second stage of growth of the fruit and the start of the slower rate of growth in stage 3, the endosperm had been completely absorbed. Ten days later, seeds were developed enough to be germinated.

No cause and effect is implied in these interrelationships, only coincidental occurrences. 


\section{LITERATURE CITED}

1. Aala, F.T. 1953. Effects of hand pollination on the production of Siamese pummelo. Philippine Jour. Agr. 18: $101-113$.

2. Abbott, C.E. 1935. Blossom-bud differentiation in citrus trees. Am. Jour. Bot. 22:476-485.

3. Abeles, F.B. and R.E. Holm. 1966. Enhancement of RNA synthesis, protein synthesis, and abscission by ethylene. Plant Physiol. 41 (8):1337-1342.

4. and 1967. Abscission: Role of protein synthesis. An. of the New York Acad. Sci. $144(1): 367-373$.

5. Addicott, F.T. 1961. Gibberellic acid and abscission. Calif. Agr. 15(9):4.

6. H. Carns, J. Lyon O. Smith, and J. McMeans. 1964. On the physiology of abscisin. Center National de Ia Hecherche Scientifique, Paris.

7. and R. Lynch. 1951. Acceleration and retardation of abscission by indoleacetic acid. Sci. $114: 688-689$.

8. and 1955. Physiology of abscission. Ann. Rev. Plant Physiol. 6:211-238.

9. gradient theory of abscission regulation. Sci. 121:644.

10. J. Lyon, and O. Smith. 1962. On the physiological nature of abscisin and other abscission accelerating substances, Plant Physiol. (supplement) 37: xxxvi.

11. O. Smith, and J. Lyon. 1965. Some physiological properties of abscisin II. Plant Physiol. (supplement) 40:xxvi-xxvii.

12. Anonymous. 1967. Smog reduces yield, causes fruit droppage. Citrus World 3(11):18. 
13. Attia, M.S. 1950. The nature of incompatibility in cabbage. Proc. Amer. Soc. Hort. Sci. 56:369-371.

14. Babenko, V. 1956. Initiation and differentiation of fruit buds on lemons in trenches and lemons in unheated glass houses. Hort. Abst., $29(2): 1831$.

15. Bacchi, 0. 1943. Cytological observations in citrus: II. Megasporogenesis, fertilization, and polyembryony. Bot. Gaz. 105:221-225.

16. Bain, J.M. 1958. Morphological, anatomical, and physiological changes in the developing fruit of the Valencia orange, Citrus sinensis (L.) Osbeck. Aust. Jour. Bot. 6:1-24.

77. Banerji, I. 1954. Morphological and cytological studies on Citrus grandis Osbeck. Phytomorphology $4: 390-396$.

18. Barlow, H. 1950. Studies in abscission. I. Factors affecting the inhibition of abscission by synthetic growth substances. Jour. Expt1. Bot. 1:264-281.

19. Barnell, E. 1939. Studies in tropical fruits. V. Some anatomical aspects of fruit fall in two tropical aboreal plants. An. Bot. 3:77-89.

20. Batholomew, E. 1923. Internal decline of lemons. II. Growth rate, water content, and acidity of lemons at different stages of maturity. Amer. Jour. Bot. 10:117-126.

21. and H. Reed. 1946. General morphology, histology, and physiology. In The Citrus Industry by H. Webber and L. Batchelor, vol. 1, chap. vi, pp. 669717, Univ. Calif. Press, Berkeley, Calif.

22. Biggs, R.H 1957. Physiological basis of abscission in plants. Doctoral Dissertation, Purdue University, Lafayette, Indiana.

23. and A. Leopold. 1957. Factors influencing abscission. Plant Physiol. 32:626-632.

24. and 1958. The two-phase action of auxin on abscission. Amer. Jour. Bot. 45:547-551.

25. Bormman, C. and F. Addicott. 1965. Histological and histochemical effects of auxin and gibberellin in abscission. Plant Physiol. (supplement) 40:xxvil.

26. A. Spurr, and F. Addicott. 1967. Abscisin, auxin, and gibberellin effects on the developmental aspects of abscission in cotton. Amer. Jour. Bot. 54:125135 . 
27. Boyle, H. 1914. Notes on the Siamese pomelos. Philippine Agr. Rev. 7(2):65-69.

28. Brewbaker, J. and S. Majumder. 1961. Cultural studies of the pollen population effect. Amer. Jour. Sci. $48: 57-64$.

29. Brink, R. 1924. The physiology of pollon. Amer. Jour. Bot. $11: 417-436$.

30. Brown, H. and F. Addicott. 1950. Anatomy of experimental leaflet abscission in Phaseolus vulgaris. Amer. Jour. Bot. $37: 650-656$.

31. Burkholder, C. and M. MCCown. 1941. Effects of scoring and of anaphtinaleneacetic acid and amide spray upon fruit set and of the spray upon preharvest fruit drop. Proc. Amer. Soc. Hort. Sci. 38:117-120.

32. Carlos, J.T. and A.H. Krezdorn. 1968. Fruit set and seed production of self-incompatible citrus as affected by pre-anthesis pollination, Proc. Amer. Soc. Hort. Sci. Trop. Reg., 16th Ann. Meet. (In press).

33. Carns, H., F. Addicott, K. Baker, and R. Wilson. 1961. Acceleration and retardation of abscission by gibberellic acid. In Plant Growth and Regulation, Iowa State Univ. Press, Ames, Iowa.

34.

of water and' oxygen on' abscission in vitro. Plant Physiol. 26:629-630.

35. Carpenter, W. 1956. Influence of plant hormones on the abscission of poinsettia leaves and bracts. Proc. Amer. Soc. Hort. Sci. 67:539-544.

36. Chatterjee, S. and A. Leopold. 1963. Auxin stmucture and abscission activity. Plant Physiol. 38:268-273.

37. and 1964. Kinetin and gibberellin actions on abscission processes. Plant Physiol. 39: $334-337$.

38. Chaudhri, S. 1957. Some anatomical aspects of fruit drop in citmus. Doctoral Dissertation, Univ. Fla., Gainesville, Fla.

139. Coit, J.E. 1914. Citriculture. Univ. Calif. Agr. Expt. Sta. Ann. Rep. pp.105-106.

40. and R. Hodgson. 1919. An investigation of the abnormal shedding of young fruits of the Washington navel orange. Calif. Univ. Publ. Agr. Sci. 3:199-207. 
41. Coggins, C., H. Hield, and S. Boswell. 1960. Influence of potassium gibberellate on Lisbon trees and fruits. Proc. Amer. Soc. Hort. Sci. 76:199-207.

42. , and R. Burns. The influence of potassium gibberellate on grapefruit trees and fruits. Proc. Amer. Soc. Hort. Sci. 81:223-226.

43. , and M. Garber. 1960. Influence of potassium gibberellate on Valencia orange trees and fruits. Proc. Amer. Soc. Hort. Sci. 76:193-198.

44. Cooper, J. 1928. The behavior of pollen tubes in selfand cross-pollinations. Proc. Amer. Soc. Hort. Sci. $25: 138-140$.

45. Cormack, R. 1955. Action of pectic enzymes on surface cells of living Brassica roots. Sci. 122:1019-1020.

46. Cornforth, J., B. Milborrow, and G. Ryback. 1965. Synthesis of abscisin II. Nature 205:715.

47. , , and P. Wareing. 1965. Identity of sycamore dorminwith abscisin II. Nature 205(4978): 1269-1270.

48. Crane, J. 1956. The comparative effectiveness of several growth regulators for controlling preharvest drop, increasing size, hastening maturity of Stewart apricots. Proc. Amer. Soc. Hort. Sci. 67:153-159.

49. Crowe, A. D. 1965. Effect of thinning sprays on metabolism of growth substances in the apple. Proc. Amer. Soc. Hort. Sci. 86:23-27.

50. Dennis, F. and L. Edgerton. 1962. Induction of parthenocarpy in the apple with gibberellin and the effects of supplementary auxin application. Proc. Amer. Soc. Hort. Sci. 80:58-63.

51. and 1966. Effects of gibberellins and ringing upon apple fruit development and flower bud formation. Proc. Amer. Soc Hort. Sci. 88:14-24.

52. Donoho, C. and F. Hartman. 1965. Influence of thinning chemicals on fruit set, yield, return bloom, fruit russetting, and tree growth of Jonathan and Golden Delicious apple. Abst. Proc. Amer. Soc. Hort. Sci. 62nd Ann. Meet., 1965.

53. Dunlap, A. 1943. Low 1ight intensity and cotton boll-shedding. Sci. 98:568-569.

54. Dutt, C. 1938. Abscission in cotton flowers. Bot. Gaz. $85: 208-220$. 
55. Eames, A. and L. MacDaniels. 1947. An Introduction to Plant Anatomy McGraw-Hill Book Co., Inc., New York.

56. East, E. 1929. Self-sterility. Bibliog. Genetics. $5: 331$.

57. and A Mangelsdorf. 1925. A new interpretation of the hereditary behavior of self-sterile plants. Proc. Nat. Acad. Sci. 11:166-171.

58. and J. Park. 1918. Studies on self-sterility: II. Polien tube growth. Genetics. 3:353-366.

59. Eaton, F. and D. Ergle. 1953. Relationships of seasonal trend in carbohydrate and nitrogen levels and effects of girdling and spraying with sucrose and urea to the nutritional interpretation of boll-shedding in cotton. Plant Physiol. 28:503-520.

60. Edgerton, L. and M. Hoffman. 1951. The effectiveness of several growth regulating chemicals in delaying the harvest drop of the McIntosh apple. Proc. Amer. Soc. Hort. Sci. 57:120-124.

61. and 1963. Influence of some growth regulating substances on fruit set in the McIntosh apple. Proc. Amer. Soc. Hort. Sci. 83:6367.

62. Elliott, F. 1958. Plant Breeding and Cytogenetics. McGraw-Hill Book Co., Inc., New York.

63. Emerson, S. 1940. Growth of incompatible pollen tubes in Oenothera. Bot. Gaz. 101:890-911.

64. Emsweller, S. and N. Stewart. 1948. Use of growth regulating substances to overcome incompatibilities in Lilium. Proc. Amer. Soc. Hort. Sci. 51:581-589.

65. Erickson, L. 1951. Effects of 2,4-D on drop of sound and unsound Washington navel oranges. Proc. Amer. Soc. Hort. Sci. 58:46-52.

66. and B. Brannaman. 1960. Abscission of reproductive structures and leaves of orange trees. Proc. Amer. Soc. Hort. Sci. 75:222-229.

67. _, and H. Hield. 1952. Response of Delicious and Rome Beauth apples to a preharvest spray of 2,4,5-TP in southern California. Proc. Amer. Soc. Hort. Sci. 60:160-164.

68. Esau, K. 1961. Anatomy of Seed Plants. John Wiley \& Sons, Inc., New York. 
69. Eyster, W. 1941. The induction of fertility in genetically self-sterile plants. Sci. 94(2432):144-145.

70. Facey, V. 1950. Abscission of leaves in Fraxinus americana L. Phyto. 49:103-116.

71. Farnham, R. 1935. Factors associated with bud-drop of sweet peas and methods of control. Proc. Amer. Soc. Hort. Sci. 33:655-662.

72. Ford, E.S. 1942. Anatomy and histology of the Eureka lemon. Bot. Gaz. 104:288-305.

Frost, H. 1926. Polyembryony, heterozygosis, and chimeras in citrus. Hilgardia 1:365-402.

74. 1946. Seed reproduction: Development of the gametes and embryos. In The Citrus Industry by H. Webber and L. Batchelor, vol.1, chap.viii, pp. 767815. Univ. Calif. Press, Berkeley, Calif.

75. Furr, J., C. Taylor, and P. Reece. 1939. Fruit set of citrus. Effect of spring soil moisture upon drop of young fruit. Proc. Amer. Soc. Hort. Sci. 37:152-157.

76. Gaur, B. and A. Leopold. 1955. Promotion of abscission by auxin. Plant Physiol. 30:487-490.

77. Gawadi, A. and G. Avery. 1950. Leaf abscission and the so-called abscission layer. Amer. Jour. Bot. 37: 172-180.

78. Gortner, R. and J. Harris. 1914. On the axial abscission in Impatiens sultani as a result of a traumatic stimuli. Amer Jour. Bot. 1:48-50.

79. Griggs, W.H. and B.T. Iwakiri. 1961. Effects of gibberellin and 2,4,5-TP sprays on Bartlett pear trees. Proc. Amer. Soc. Hort. Sci. 77:73-89.

80. Hall, W. 1952. Evidence on the auxin-ethylene balance hypothesis of foliar abscission. Bot. Gaz. 113: $310-322$.

81. Hassabala, I.A. 1964. Growth substances as related to fruit set and development of seedy and nonseedy cultivars of citrus. Doctoral Dissertation, Univ. Fla., Gainesville, Fla.

82. Hayes, H. and R. Garber. 1927. Breeding Crop Plants. McGraw-Hill Book Co., Inc., New York. 
83. Hensz, R. 1964. A morphological and physiological investigation of the self-incompatibility of the

'Orlando' tangelo. Doctoral Dissertation, Univ. Fla., Gainesville, Fla.

84. Hield, H., R. Burns, and M. Garber. 1965. Effect of gibberellin sprays on fruit set of Washington navel orange trees. Hilgardia 36:297-311.

85. Hodgson, R. 1918. An account of the mode of foliar abscission in citrus. Univ. Calif. Publ. Bot. 6(15): $477-428$.

86. Hoshaw, R. and A. Guard. 1949. Abscission of marcescent leaves of Quercus palustris and $\underline{\text {. }}$ coccinea. Bot. Gaz. $110: 578-593$.

87. Jacobs, W. 1955. Studies on abscission: Physiological basis of the abscission-speeding effect of intact leaves. Amer. Jour. Bot. 42:594-603.

88. $\overline{116(5): 3-7}:$

1955a. What makes leaves fall? Sci. Amer.

89. - 1962. Longevity of plant organs: internal factors controlling abscission. Ann. Rev. Plant Physiol. 13:403-436.

90. 1964. Does auxin inhibit the abscission of coleus leaves by acting as a growth hormone?

Amer. Jour. Bot. 51:893-897.

91. C. McCready, and D. Osborne. 1966. Transport of the auxin 2,4-D through abscission zones, pulvini, and petioles of Phaseolus vulgaris. Plant Physiol. 41: 725-730.

92.

$$
\text { J. Shield, and }
$$
1962. Senescence factor and abscission of coleus leaves. Plant Physiol. $37: 104-106$.

93. Jensen, W. 1962. Botanical Histochemistry. W.H. Freeman and Co., San Francisco, Calif.

94. Johansen, D. 1940. Plant Microtechnique. McGraw-Hill Book Co., Inc. New York.

95. 1950. Plant Embryology. Chronica Botanica Co. Waltham, Mass.

96. Johnson, $R$. and J. Lyon. 1962. Abscission as influenced by growing temperature and seedling age with reference to acceleration induced by gibberellin. Plant Physiol. (supplement) $37: x x x v i$. 
97. Johnson, S. 1956. Influence of growth regulators on setting of tomato fruits: a concept. Proc. Amer. soc. Hort. Sci. 67:365-368.

98. Jones, C. 1965. Effects of benzyladenine on fruit set in muskmelon. Proc. Amer. Soc. Hort. Sci. 87: $335-340$.

99. Kendall, J. 1918. Abscission of flowers and fruits in the Solanaceae with special reference to Nicotiana. Univ. Calif. Publ. Bot. 5:347-428, 439-450.

100. Koslova, N. 1960. Certain morphological characteristics associated with the development of generative organs and seeds of the sour cherry (Prunus cerasus) Bot. Zurnal 45:84-89.

101. Krezdorn, A.H. 1960. Factors affecting unfruitfulness of 'Orlando' tangelos. Fla. Agr. Expt. Sta. Ann. Rep. p. 140 .

102.

fruit-set sprays on yield and quality of citrus. Proc. Fla. State Hort. Soc. 75:53-60.

103. and F. Robinson. 1958. Unfruitfulness in the 'Orlando' tangelo. Proc. Fla. State Hort. Soc. $71: 86-91$.

104. Laudi, G. 1956. Studies on the physiology of abscission: Influence of intact branches, leaves, and axillary buds on the abscission of debladed petioles. Nuovo Siorn. Bot. Stal. 63:204-212,

105. Laurie, A. and J. Duffy. 1948. Anatomical studies of the abscission of gardenia buds. Proc. Amer. Soc. Hort. Sci. 51:575-580.

106. Leopold, A.C. 1964. Plant Growth and Development. McGraw-Hil1 Book Co., Inc., New York.

107. B. Rubinstein, W. Liu, and H. Carns. 1961. Abscission and abscisin. Sci. 134(3493):1883-1884.

108. Leuty, S. and M. Bukovac. 1968. The effect of naphthaleneacetic acid on abscission of peach fruits in relation to endosperm development. Proc. Amer. Soc. Hort. Sci. 92:124-134.

109. Lewis, D. 1942. The physiology of incompatibility in plants. Proc. Roy. Soc. Bot. 131:13. 
110. 1946. Chemical control of fruit formation. Jour. Pom. and Hort. Sci. 22:175-183.

111. 1949. Incompatibility in flowering plants. Biol. Rev. 24:472-496.

112. and L. Crowe. 1954. The induction of selffertility in tree fruits. Jour. Hort. Sci. 29:220-225.

113. Lloyd, F. 1916. Abscission in Mirabilis jalapa Bot. Gaz. $61: 213-230$.

114. Lombard, P.B. and A.B. Mitche11. 1962. Anatomical and hormonal development in Redhaven peach seeds as related to the timing of naphthaleneacetic acid for fruit thinning. Proc. Amer. Soc. Hort. Sci. 80:163171.

115. Lott, R. and R. Simons. 1964. Floral tube and style abscission in peach and their use as physiological reference points. Proc. Amer. Soc. Hort. Sci. 85: $141-153$.

116. and 1966. Sequential development of floral tube and style abscission in the Montmorency cherry (Prunus cerasus). Proc. Amer. Soc. Hort. Sci. $88: 208-218$.

117. Luckwill, L. 1948. The hormone content of seed in relation to endosperm development and fruit drop in apple. Jour. Hort. Sci. 24:32-44.

118. 1953. Studies of fruit development in relation to plant hormones. I. Hormone production by developing apple seed in relation to fruit drop. Jour. Hort. Sci. 28:14-24.

119. MacDaniels, L. 1936. Some anatomical aspects of apple flower and fruit abscission. Proc. Amer. Soc. Hort. Sci. 34:122-129.

120. Maheshwari, P. 1950. Introduction to the Embryology of Angiosperms. MoGraw-Hill Book Co. Inc., New York.

121. Majsuradze, N. 1961. Growth of sexual and nucellar seeds of sweet orange. Agrob. No. 2, 309-310.

122. Mamporija, F. 1957. The effect of the male parent on the nucellar cells of citrus. Agrob. 5:119-131.

123. Mather K. 1944. Genetical control of incompatibility in angiosperm and fungi. Nature, London, 153:312. 
124. Mason, T. 1922. Growth and abscission in Sea Island cotton. An. Bot. 36:457-484.

125. McCown, M. 1937. Observations on the abscission of the mature fruits of some apple varieties. Proc. Amer: Soc. Hort. Sci. 35:48.

126. Modlibowska, I. 1945. Pollen tube growth and embryosac development in apples and pears. Jour. Pom. and Hort. Sci. 21:57-89.

127. Monselise, S. and A. Halevey. 1964. Chemical inhibition and promotion of citrus bud induction. Proc. Amer. Soc. Hort. Sci. 84:141-146.

128. Muir, R. and J. Valdovinos. 1965. Gibberellin and auxin relationships in abscission. Plant Physiol. (supplement) 40:xxvi.

129. Mustard, M., S. Lynch, and R. NeIson. 1956. Pollination and floral studies of the 'Minneola' tangelo. Proc. Fla. State Hort. Soc. 69:277-281.

130. Nassar, A. and W. Kliewer. 1966. Free amino acids in various parts of Vitis vinifera at different stages of development. Proc. Amer. Soc. Hort. Sci. 89:281294.

131. Nightingale, $F$. and R. Farnham. 1936. Effects of nutrient concentration on anatomy, metabolism, and bud abscission of sweet pea. Bot. Gaz. 97:477-517.

132. Okhuma, K. 1965. Synthesis of some analogs of abscisin II. Agr. Ciol. Chem. 29:962-964.

133. J. Lyon, and F. Addicott. 1963. Abscisin II and abscission-accelerating substances from young cotton fruit. Sci. 142:1592-1593.

134. Olez, H. and Q. Zielinski. 1965. Pollen incompatibility between Bartlett and Seckel pears. Proc. Amer. Soc. Hort. Sci. 87:117-122.

135. Oppenheimer, H.R. 1948. Experiments with unfruitful Clementine mandarins in Palestine. Bul. 48, Agr. Res. Sta., Rehovot, Israel.

136. Osawa, I. 1912. Cytological and experimental studies in citrus. Jour. Col. Agr. Tokyo 4:83-116.

137. Osborne, D. 1955. Acceleration of abscission by a factor produced in senescent leaves. Nature. 176: $1161-1163$. 
138. and S. Moss. 1963. Effect of kinetin on senescence and abscission in explants of Phaseolus vulgaris. Nature 200:1299-1301.

139. Pearson, O.H. 1929. Observations on the type of sterility in Brassica oleracea var. capitata. Proc. Amer. Soc. Hort. Sci. 26:34-38.

140. Randhawa, G. and H. Dinsa. 1947. Time of blossombud differentiation in citrus. Proc. Amer. Soc.

Hort. Sci. 50:165-171.

141. Reece, P. 1945. Fruit set in the sweet orange in relation to flowering habit. Proc. Amer. Soc. Hort. Sci. 46 : $81-86$.

142. and R. Register. 1961. Influence of pollinations on fruit set of Robinson and Osceola tangerines. Proc. Fla. State Hort. Soc. 74:104-106.

143. Rubinstein, B. and F. Abeles. 1965. Relationship between ethylene evolution and leaf abscission. Bot. Gaz. $126(4): 255-259$.

144. and A. Leopold. 1962. control of leaf abscission by auxin. (supplement) $37: x \times x v i$.

145. and 1963. Analysis of the auxin control of bean leaf abscission. Plant Physiol. $38: 262-267$.

146. Sacher, J. 1957. Relationship between auxin and membrane integrity in tissue senescence and abscission. Sci. 125: 1199-1200.

147. Scott, F., M. Schroeder, and F. Turre11. 1948. Development of cell shape, suberization of internal surface, and abscission in the leaf of the Valencia orange, Citmus sinensis. Bot. Gaz. 109:381-411.

148. Scott, P. and A. Leopold. 1965. Petiole abscission as a localized cell senescence. Plant Physiol. (supplement) 40:xxv.

149. and 1966. Abscission as a mobilization phenomenon. Plant Physiol. 41:826-830.

150. Sears, E. 1937. Cytological phenomena connected with self-sterility in flowering plants. Genetics. 22:130.

151. Shavit, A. 1956. An investigation into the process of flower and fruit abscission of the Shamouti orange. Bul. Res. Coun. of Israel 5D:189-199. 
152. Shoji, K, F. Addicott, and W. Swets. 1951. Auxin in relation to leaf blade abscission. Plant Physiol. 26:189-191.

153. Smith, J. 1935. Abscission of sweet pea flower buds. Proc. Amer. Soc. Hort. Sci. 33:663-668.

154. Soost, R. 1956. Unfruitfulness in the clementine mandarin. Proc. Amer. Soc. Hort. Sci. 67:171-175.

155. 1964. Self-incompatibility in Citrus grandis (L) Osbeck. Proc. Amer. Soc. Hort. Sci. 84:137-140.

156. 1965. Incompatibility alleles in the genus Citrus. Proc. Amer. Soc. Hort. Sci. 87:176-180.

157. and R. Burnett. 1961. Effects of gibberellin on yield and fruit characteristics of clementine mandarin. Proc. Amer. Soc. Hort. Sci. 77:194-201.

158. Southwick, F., I. Demoranville, and J. Anderson. 1953. The influence of some growth regulators on pre-harvest drop, color, and maturity of apples. Proc. Amer. Soc. Hort. Sci. 61:155-162.

159.

and W. Weeks. 1957. The effects of several growth regulators on the preharvest drop and softening of apples. Proc. Amer. Soc. Hort. Sci. 69:41-47.

160. of naphthaleneacetic acid type materials and 1 -napthyl $\mathrm{N}$-nethylcarbamate (sevin) on the fruiting, flowering, and keeping quality of apple. Proc. Amer. Soc. Hort. Sci. $84: 14-24$.

161. , E. Sawada, and J. Anderson. 1962. The influence of chemical thinners and seeds on the growth rate of apples. Proc. Amer. Soc. Hort. Sci. $80: 33-42$.

162. Stout, A.B. 1938. The genetics of incompatibilities in homomorphic flowering plants. Bot. Rev. 4:275-369.

163. Swen, M. 1933. Factors affecting flower shedding in soybeans. Doctoral Dissertation, Univ. I11., Urbana, III.

164. Terpstra, W. 1956. Some factors influencing the abscission of debladed leaf petioles. Acta Bot. 5(2):

$157-170$.

165. Thompson, C. and O. Taylor. 1967. Reduction of fruit drop by navel oranges with anti-oxidant dusts and girdling. Hort. Science 2(3):103-104. 
166. Ton, L.D. 1965. Sexual incompatibility in several varieties of citrus. M.S. Thesis, Univ. Fla., Gainesville, Fla.

167. and A. H. Krezdorn. 1966. Growth of pollen tubes in three incompatible varieties of citrus. Proc. Amer. Soc. Hort. Sci. 89:211-215.

168. Torres, J. 1932. Progress report on citrus hybridization. Philippine Jour. Agr. 3:217-229.

169. Toxopeus, H. 1931. Cited by Frost, 1946. In The Citrus Industry, vol. 1, chap. viii, pp. 767-815. Univ. Calif. Press, Berkeley, Calif.

170. Traub, H, 1936. Artificial control of nucellar embryony in citrus. Sci. 83:165-166.

171. Van Schaik, P. and A. Probst. 1958. Effect of some environmental factors on flower production and reproductive efficiency of soybeans. Agron. Jour. 50:192-197.

172. Watanabe, K. 1961. Studies on the germination of grass pollen. II. Germination capacity of the pollen in relation to the maturity of pollen and stigma. Bot. Mag. 74:131-137.

173. Waynick, D. 1927. Growth rates of Valencia oranges. Calif. Citrog. 12:150-164.

174. Webber, H. 1900. Complication in citrus hybridization caused by polyembryony. Sci. 11:308.

175. 1931. The economic importance of apogamy in Citrus and Mangifera. Proc. Amer. Soc. Hort. Sci. 28: $57-61$.

176. 1930. The influence of pollination on set of fruit in citrus. Calif. Citrog. 15:304,322,323.

177. 1946. History and development of the citrus industry. In The Citrus Industry, vol. 1. chap.i, pp.140, Univ. Calif. Press, Berkeley, Calif.

178. Weller, L., R. Lueke, C. Hammer, and H. Shell. 1950. Changes in chemical composition of the leaves and roots of red kidney bean plants treated with 2,4-D. Plant Physiol. 25:289-293.

179. Wilson, W. 1966. The anatomy and physiology of citrus fruit abscission induced by iodoacetic acid. Doctoral Dissertation, Univ. Fla., Gainesville, Fla. 
180. Wiltbank, W. 1967. Seasonal changes in gibberellinlike compounds in ovaries and young fruits of navel orange. Doctoral Dissertation, Univ. Fla., Gainesville, Fla.

181. Wittwer, S., M. Bukovac, H. Sell, and L. Weller. 1957. Some effects of gibberellin on flowering and fruit setting. Plant Physiol. 32:39-41.

182. Yager, R. 1960. A comparison of the mode of floral abscission in two varieties of Nicotiana tabacum. Proc. Iowa Acad. Sci. 67:86-91.

183. - 1960a. Possible role of pectic enzymes in abscission. Plant Physiol. 35(2):157-162.

184. 1960b. Some effects of leaves and indoleacetic acid upon floral abscission in Nicotiana tabacum. Bot. Gaz. 121:244-249.

185. Yasuda, S. 1930. Physiological researches on the fertility of Petunia violacea. $X$. On the relation between the self-incompatibility and the tissue juice of the ovary. Bot. Mag. Tokyo 46:510-517.

186. 1932. A method of obtaining self-fertilized seeds in self-incompatible plants. Proc. Crop Sci. Jap. $2(2): 122-126$.

187. Yermanos, D.M. and J. Davidson. 1964. Flower and capsule abscission in flax (Linum usitatissimum). Agron. Jour. 56:442.

188. Zeller, O. 1964. Developmental rhythms of fruit crops in Finland. I. Developmental rhythms of 5 cultivated varieties of Malus communis and of Prunus padus. Hort. Abst. 35:301. 


\section{BIOGRAPHICAL SKETCH}

Juan Tabilangon Carlos, Jr. was born on June 16, 1935, at Sta. Lucia, Capas, Tarlac, Philippines. In March, 1955, he graduated with honors from the Tarlac High School. He was an entrance scholar in the College of Agriculture, University of the Philippines from which he received the Bachelor of Science degree with major in Agricultural Economics (Honors Curriculum) in March, 1960. In June, 1960, he was accepted to the Graduate School of the University of the Philippines and awarded a fellowship. He finished requirements for the Master of Science degree in Horticulture in December, 1962.

The author has been an instructor in the college of Agriculture, University of the Philippines since June, 1962. He has been on a leave-of-absence from the same institution since August, 1965 when he was awarded a Rockefeller Foundation Fellowship to work toward the degree of Doctor of Philosophy in the University of Florida.

Juan T. Carlos, Jr. is a member of the Gamma Sigma Delta Honor Society of Agriculture, Honor Society of the Phi Kappa Phi, Phi Sigma Biological Society, Los Banos Biological Club, American Institute of Biological Sciences, and the American Society of Horticultural Science. He is married to the former Anastacia Dungca Balagtas. They have three children: Melvin, Ariel, and Butch. 
This dissertation was prepared under the direction of the chairman of the candidate's supervisory committee and has been approved by all members of that committee. It was submitted to the Dean of the College of Agriculture and to the Graduate Council, and was approved as partial fullfillment of the requirements for the degree of Doctor of Philosophy.

December, 1968

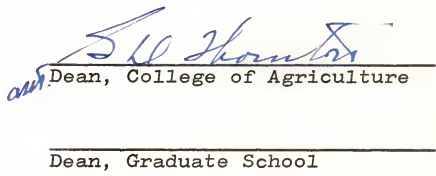

Supervisory Committee:

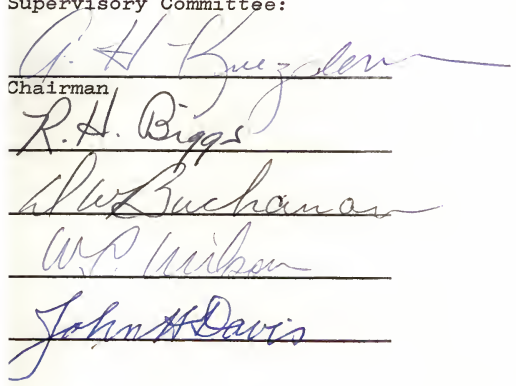

